\title{
Stability of Volcanic Slopes in Cold Regions
}

\author{
Shima Kawamura ${ }^{1} \&$ Seiichi Miura ${ }^{2}$ \\ ${ }^{1}$ Graduate School of Engineering, Muroran Institute of Technology, Muroran, Japan \\ ${ }^{2}$ Graduate School of Engineering, Hokkaido University, Sapporo, Japan \\ Correspondence: Shima Kawamura, Graduate School of Engineering, Muroran Institute of Technology, Muroran, \\ 27-1 Mizumoto-cho, 050-8585, Japan. Tel: 81-143-46-5282. E-mail: skawamur@mmm.muroran-it.ac.jp
}

Received: April 4, 2014 Accepted: May 19, 2014 Online Published: June 25, 2014

doi:10.5539/jgg.v6n3p34 URL: http://dx.doi.org/10.5539/jgg.v6n3p34

\begin{abstract}
Rainfall- and earthquake-induced failures of slopes formed by volcanic soils occur frequently in Hokkaido, Japan. This study aims at clarifying failure mechanisms of volcanic slopes caused by both rainfall and freeze-thaw action in cold regions such as Hokkaido. Additionally, the mechanical behavior of volcanic slopes pre-deformed due to cyclic loadings such as seismic loadings were examined to elucidate the effect of initial water content on rainfall-induced failure of volcanic slopes. Using model slopes of different shapes constructed with volcanic soils, a series of model tests was conducted under several conditions in which spray nozzles and a shaking table were used to simulate rainfall intensity and cyclic loadings. Test results showed that surface failure of volcanic slopes differed depending strongly on their initial moisture content. Based on the results of model testing, the effects of freezing and thawing and cyclic loadings on mechanisms of rainfall-induced failure were drawn upon to propose an evaluation method for slope stability. The model test results indicated that rainfall-induced failure can be uniquely assessed by changes in water content in zones subjected to freezing and thawing or to shearing deformation due to cyclic loadings.
\end{abstract}

Keywords: cyclic loadings, freeze-thaw action, model test, rainfall, slope failure, volcanic soils

\section{Introduction}

In Hokkaido, Japan, there are over forty Quaternary volcanoes, and pyroclastic materials cover over $40 \%$ of the prefectural area. The volcanic soils have been utilized as a useful construction material, especially for man-made earth structures (embankments and cut slopes, etc.). In recent decades, although volcanic soils have been classified as "problematic soils" in Japan engineering research pertaining to these soils have been limited in comparison with cohesion and cohesionless soils (e.g., Miura, Yagi, \& Asonuma, 2003).

Recently, earthquakes and heavy rainfall in Hokkaido have been a leading cause of serious ground, natural slope, cut slope, and embankment damage; particularly where these are composed of volcanic soils (e.g., Japanese Geotechnical Society [JGS], 2004). Examples include embankment slope failures due to the 2003 Tokachi-oki earthquake, cut slope failure on the Hokkaido Expressway (1999), and embankment failure on the Route 230 Nakayama Mountain Pass due to rainfall and snow-thaw water in the spring of 2012 and 2013 (Yamazaki, Tomojiri, \& Sasaki, 2000; Kudo, 2013).

A significant amount of research has been accumulated on the mechanisms of slope failure induced by rainfall (e.g., Orense, Farooq, \& Towhata, 2004; Olivares et al., 2009; Huang, Lee, Ho, Chiu, \& Cheng, 2012; Cascini, Cuomo, Pastor, \& Sacco, 2013) and by earthquakes (e.g., Oka, Tsui, Kimoto, \& Kato, 2012; Mori, Tobita, \& Okimura, 2012; Okamura, Tamamura, \& Yamamoto, 2013). However, research on volcanic slopes has not progressed substantially in terms of the development of new findings due to the particular characteristics of their mechanical behavior (e.g., Uzuoka, Sento, Kazama, \& Unno, 2005; Unno, Kazama, Uzuoka, \& Sento, 2006; Kazama, Kataoka, \& Uzuoka, 2012). Similarly, in-situ experimental and analytical studies on slope stability due to the freeze-thaw sequence have also been limited (e.g., Harries \& Davies, 2000), although geotechnical problems due to frost-heaving and thawing action have been reported in a number of studies (e.g., Japanese Geotechnical Society [JGS], Hokkaido Branch, 2010).

The authors have investigated rainfall-induced failures of volcanic slopes subjected to freeze-thaw action and its mechanisms (e.g., Kawamura, Miura, Ishikawa, \& Yokohama, 2010a; Kawamura \& Miura, 2013, 2014). In previous studies, a series of model tests was performed on volcanic and sandy slopes under several conditions. 

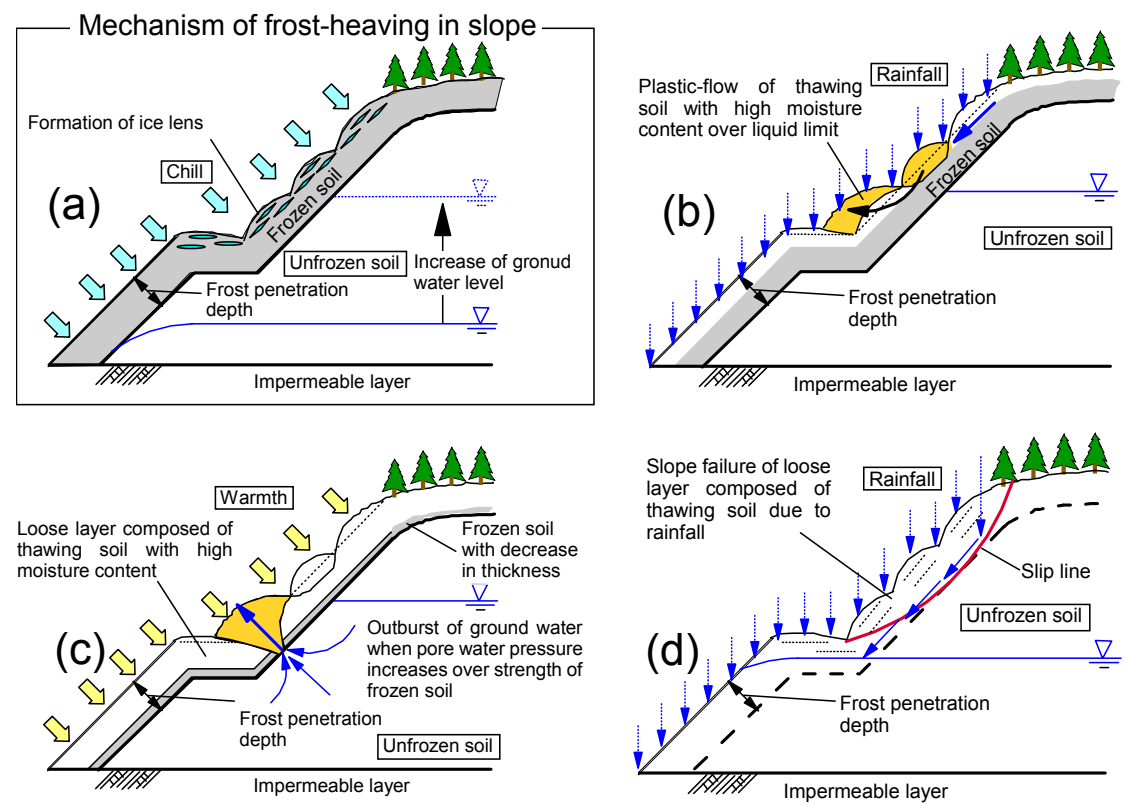

Figure 1. Mechanism of frost-heaving in cut slope observed for cold regions and failure modes: (a) mechanism of frost-heaving in slope, (b) surface failure of thawing soil with high moisture content over liquid limit (Failure pattern 1), (c) slope failure due to piping by increase of pore water pressure (Failure pattern 2), (d) slope failure of loose layer composed thawing soil due to rainfall (Failure pattern 3)

In the tests, rainfall intensities of $60 \mathrm{~mm} / \mathrm{hr}, 80 \mathrm{~mm} / \mathrm{hr}$, and $100 \mathrm{~mm} / \mathrm{hr}$ were accurately simulated through the use of spray-nozzles. During the rainfall tests, deformation and pore water pressure behavior and variation in saturation degree were monitored. The effects of the geometric condition of slopes and rainfall conditions on failure mechanisms were clarified in detail.

In addition, a series of model tests was carried out to simulate the mechanism of frost heaving and differences of failure mode in cut slopes for cold regions. Figure 1 illustrates the mechanism of frost-heaving, and three kinds of failure mode in cold regions, which are observed in field. Their phenomena were explained as follows: slopes freeze from their surface with the formation of ice lenses during the winter season (see Figure 1(a)), thereafter, the frozen soil thaws gradually from the ground surface until the summer season. In the freezing and thawing sequence, the surface layer of a slope exhibits high moisture content over the liquid limit of its soil due to the melting of snow and thawing of the ice lenses. As a result, surface failure occurs at the boundary between loose thawing soil and the frozen layer due to water infiltration from both rainfall and snowmelt because the frozen layer works as an impermeable layer (see Figure 1(b): Failure pattern 1). Another failure due to the piping phenomenon of ground water is also observed in the spring season when pore water pressure increases over the strength of the frozen layer (see Figure 1(c): Failure pattern 2). The reason for this is that the ground water level increases with the formation of a frozen layer (JGS, Hokkaido Branch, 2010). In addition, hollows of ice lenses created by thawing generate looser structures in the frozen layer compared with before the freeze-thaw process (see Figure 1(d): Failure pattern 3). Due to this phenomenon, a deeper slope failure will be induced from summer to autumn seasons.

The model test results (Kawamura et al., 2010a; Kawamura \& Miura, 2013) demonstrate that slope failures of volcanic soils depend strongly on both the angle of the slope and the friction of its impermeable layer; however, slope density was not shown to be a significant factor. It was also shown that the softening of the slope by freeze-thaw action is important for evaluating the stability of volcanic slopes; in particular, its effect is attributed to the reduction of the shearing resistance due to particle breakage and cannot be ignored for the evaluation of slope stability, and that slope failure can be predicted if the depth of frozen area and the water retention capacity in the slope are estimated by monitoring an index property such as water content.

In this study, failure mechanisms of volcanic slopes subjected to rainfall and cyclic loadings such as seismic loadings in cold regions are clarified; in particular, the effect of initial water content of volcanic soils on failure mechanisms is discussed. In addition, a prediction method for surface failure proposed by Kawamura and Miura (2013) is further expanded. Figure 2 illustrates the test scheme in this study. As shown in the figure, firstly, the 
surface failure mechanism of volcanic slopes due to rainfall was investigated to reveal the effects of the differences of initial water content on mechanical behavior and slope failure. Secondly, a series of model tests was conducted on volcanic slopes subjected to freeze-thaw actions. In particular, the effects of freezing and thawing on mechanical behavior and slope failure were examined. Finally, the mechanical behavior of volcanic slopes subjected to rainfall after cyclic loadings was clarified in order to examine the fundamentals of earthquake- and rainfall-resistant performance of slopes such as embankments. Consequently, a prediction method on surface failure is extended based on the changes in water content for several volcanic soils under various conditions.

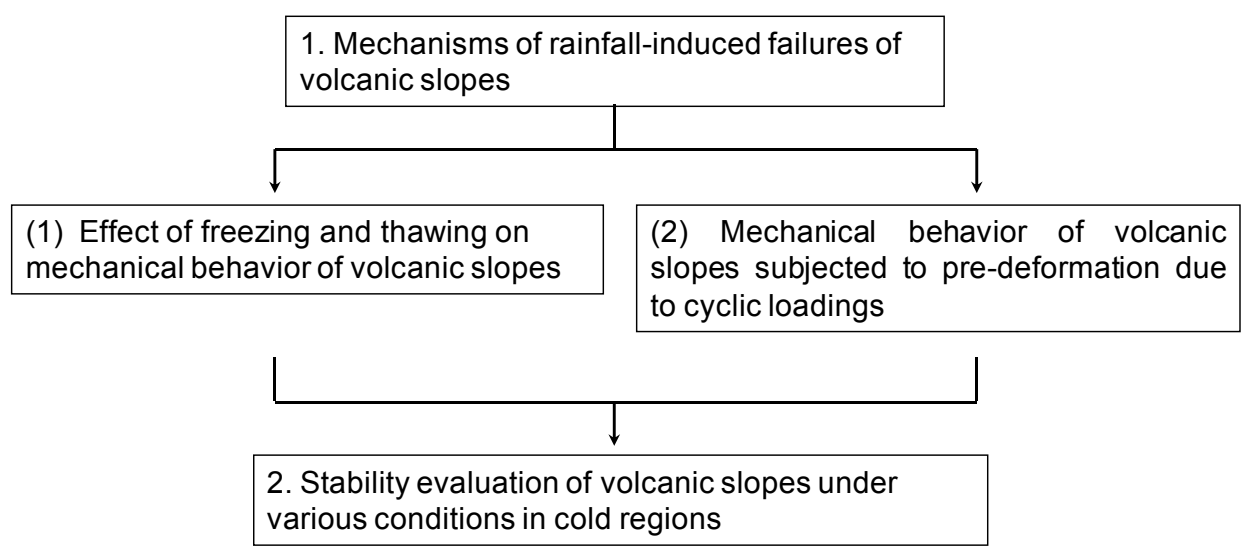

Figure 2. Test scheme and flow of discussions

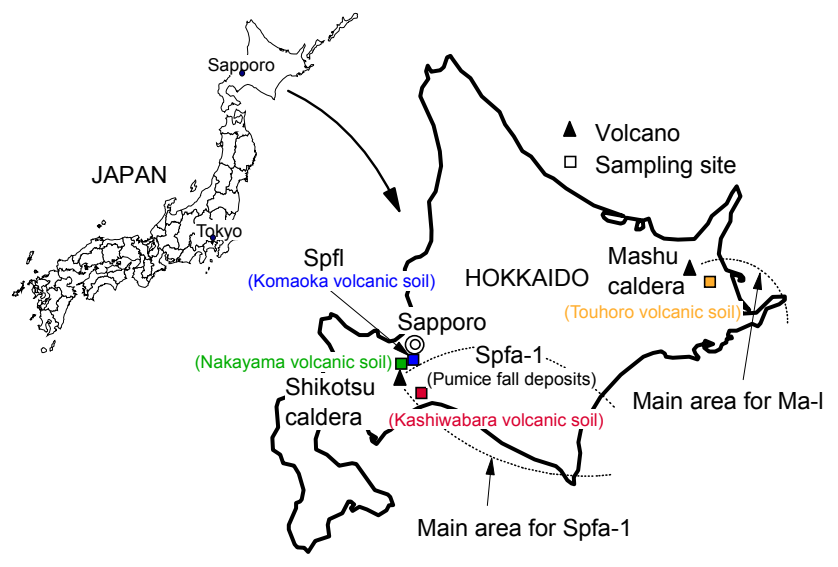

Figure 3. Locations of sampling sites

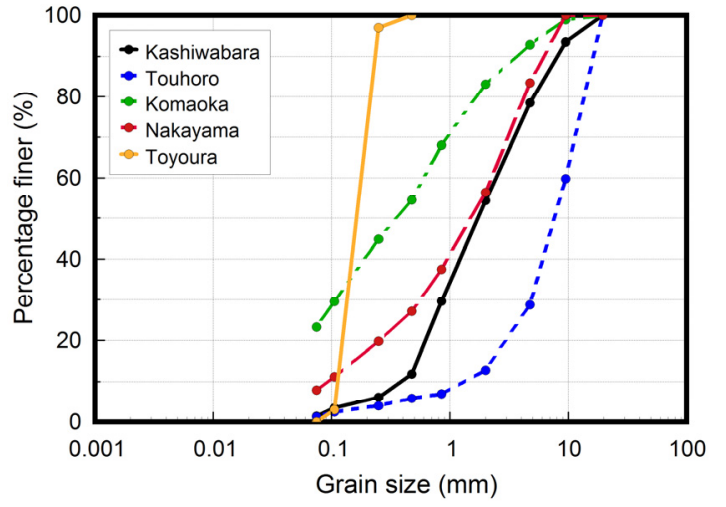

Figure 4. Grain size distributions of samples

\section{Test Materials and Test Procedures}

\subsection{Test Materials}

Volcanic coarse-grained soils used in this study were sampled from the ejecta of Shikotsu and Mashu calderas in Hokkaido and from near the site of the Nakayama Mountain Pass slope failure of 2013. Sampling sites are shown in Figure 3. These samples are hereafter referred to as Kashiwabara (Spfa-1), Komaoka (Spfl), and Touhoro (Ma-l) volcanic soils, and Nakayama volcanic soil respectively. It is estimated that the eruption age for the Kashiwabara and Komaoka volcanic soils belonging to Shikotsu primary tephra (Spfa-1, Spfl) was 31,000 34,000 years ago. Pyroclastic fall deposits which belong to the Mashu volcanic product were formed $11,000 \sim 13,000$ years ago. On the other hand, Nakayama volcanic soil consists mainly of talus deposits of lapilli tuff generated by volcano activities during the Neogene Period around the Jozankei area in Sapporo, and is utilized in the embankment as the in-situ soil material. The index properties and grain size distributions of the samples are shown in Table 1 and Figure 4, and are compared to the characteristics of Toyoura sand. As shown in Table 1 and Figure 4, their finer contents range from $1.3 \%$ to $26.0 \%$. In particular, the low value of dry 
density for Kashiwabara and Touhoro volcanic soils are also shown in the samples because their constituent particles are very porous and extremely vulnerable to crushing. On the other hand, the index property of Komaoka volcanic soil differs from that of Kashiwabara volcanic soil due to the difference in deposits (flow-deposits; Spfl and fall-deposits; Spfa-1) although they are in the same Shikotsu ejecta. Details of the mechanical behavior of these volcanic soils have been described by Miura, Yagi and Asonuma (2003), Yagi and Miura (2004) and JGS, Hokkaido Branch (2011).

Table 1. Index properties of samples

\begin{tabular}{lcccccccc}
\hline Sample name & $\rho_{\mathrm{s}}\left(\mathrm{g} / \mathrm{cm}^{3}\right)$ & $\rho_{\mathrm{d} \text { in situ }}\left(\mathrm{g} / \mathrm{cm}^{3}\right)$ & $\rho_{\mathrm{d} \max }\left(\mathrm{g} / \mathrm{cm}^{3}\right)$ & $\rho_{\mathrm{d} \min }\left(\mathrm{g} / \mathrm{cm}^{3}\right)$ & $w_{\mathrm{n}}(\%)$ & $D_{50}(\mathrm{~mm})$ & $\mathrm{Uc}$ & $\mathrm{Fc}(\%)$ \\
\hline Kashiwabara & 2.34 & 0.53 & 0.55 & 0.35 & $87-109$ & 1.3 & 3.1 & 1.3 \\
Nakayama & 2.68 & 1.47 & - & - & 25.4 & 1.6 & 22.5 & 8.0 \\
Touhoro & 2.59 & 0.44 & 0.85 & 0.52 & $106-204$ & 7.60 & 7.0 & 1.3 \\
Komaoka & 2.50 & - & 1.12 & 0.76 & 43 & 0.27 & 43.0 & 26.0 \\
Toyoura sand & 2.68 & - & 1.63 & 1.37 & - & 0.18 & 1.5 & 0 \\
\hline
\end{tabular}

$w_{n}$ : Natural water content, $D_{50}:$ Mean grain size, Uc : Coefficient of uniformity, Fc : Finer content

\subsection{Test Procedures}

It is impossible to accurately reproduce mechanical behavior in a slope due to errors (e.g., the scale effect, the soil particle effect, and the confining pressure effect, etc.) in similitude scale, especially in the $1 \mathrm{~g}$ field. However, it is an established fact that physical modeling in model testing can increase our understanding. In testing this model, it has been assumed that the strength of soil varies proportionally by the normalization of the effective confining pressure in the slope. Specifically, a conventional approach to element testing is taken in terms of the 1 g model testing (see Figure 5). Based on this technique, the mechanical behavior in the elements of the slope for the $1 \mathrm{~g}$ model corresponds with those for the real field, if rainfall intensity and seepage speed in the model are consistent with those in the prototype. Owing to this, rainfall intensity which was thought to be present in the real field was directly applied to the slope surface, and volcanic coarse-grained soils were adopted as test materials. As a result, the similarity of time dependency regarding the development of pore water pressure and the consolidation phenomenon may not be required theoretically. Additionally, note that the pore water pressure value obtained from the model test can be similarly evaluated as a true value. Consequently, reproduction by model testing is theoretically enabled, although the assumption that a model and a natural physical phenomenon occur in the same mechanism is required (Kawamura, Miura, \& Yokohama, 2010b; Kawamura \& Miura, 2013). The correlation between model and prototype in this study is summarized in Table 2.

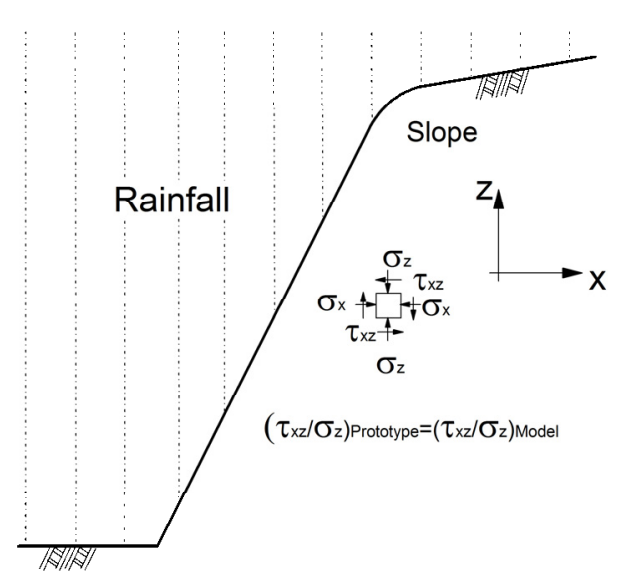

Figure 5. Test concept for $1 \mathrm{~g}$ model test 
Table 2. Correlation between model and prototype for rainfall model test

\begin{tabular}{lc}
\hline & Scale (Prototype/Model) \\
\hline Length & $\lambda$ \\
Stress ratio in element in slope & 1 \\
Pore water pressure ratio & 1 \\
Strain in element of slope & 1 \\
Deformation & $\lambda$ \\
\hline
\end{tabular}

On the other hand, for the cases of volcanic model slopes in which a shaking table was used, a series of rainfall model tests was performed on Komaoka volcanic slopes subjected to pre-deformation due to cyclic loadings to elucidate the effect of the difference of initial water content on the mechanical behavior of volcanic slopes. A similarity law is shown in Table 3, which was used for the shaking table test.

Table 3. Correlation between model and prototype for model test using a shaking table

\begin{tabular}{lc}
\hline & Scale (Prototype/Model) \\
\hline Length & $\lambda$ \\
Frequency & $1 / \lambda^{3 / 4}$ \\
Density & 1 \\
Strain & $1 / \lambda^{1 / 2}$ \\
Deformation & $\lambda^{2 / 3}$ \\
Acceralation & 1 \\
\hline
\end{tabular}

Table 4 illustrates the test conditions in this study. The following were the specific goals of the investigation:

(1) To clarify the differences in the behavior on the initial water content for each volcanic soil with freeze-thaw action or without (Case 1 Case 6 , Case 8 ).

(2) To reveal the effect of the difference of initial water content on mechanical behavior of volcanic slopes during cyclic loadings or rainfall after cyclic loadings (Case 7).

Table 4. Test conditions for this study

\begin{tabular}{|c|c|c|c|c|c|}
\hline Test case & Case1 & Case2 & Case 3 & Case 4 & Case 5 \\
\hline Sample name & Touhoro & Touhoro & Kashiwabara & Kashiwabara & Nakayama \\
\hline Slope condition & No freeze-thaw action & Freeze-thaw action & No freeze-thaw action & Freeze-thaw action & No freeze-thaw action \\
\hline Slope angle $\left({ }^{\circ}\right)$ & 55,65 & 55,65 & 65 & 65 & 45 \\
\hline Length of base, B (mm) & 572,442 & 572,442 & 442 & 442 & 400 \\
\hline Initial water content(\%) & $45,50,65,80$ & $45,65,80$ & $20,40,55,60,70$ & $20,40,55,60,70$ & 25 \\
\hline Dry density $\rho_{\mathrm{d}}\left(\mathrm{g} / \mathrm{cm}^{3}\right)$ & 0.44 & 0.44 & 0.48 & 0.48 & 1.2 \\
\hline Ranfall intensity, $\mathbf{R}(\mathrm{mm})$ & 100 & 100 & 100 & 100 & $60,80,100$ \\
\hline Freeze-thaw action cycles & - & 1 & - & 1 & - \\
\hline Other condition & - & - & - & - & - \\
\hline Test case & Case 6 & Case 7 & Case 8 & & \\
\hline Sample name & Komaoka & Komaoka & Komaoka & & \\
\hline Slope condition & No freeze-thaw action & No freeze-thaw action & Freeze-thaw action & & \\
\hline Slope angle $\left({ }^{\circ}\right)$ & 45 & 45 & 45 & & \\
\hline Length of base, $B$ (mm) & 750 & 400 & 750 & & \\
\hline Initial water content(\%) & $34,38,43$ & 37,43 & 38,43 & & \\
\hline Dry density $\rho_{\mathrm{d}}\left(\mathrm{g} / \mathrm{cm}^{3}\right)$ & 0.9 & 0.9 & 0.9 & & \\
\hline Ranfall intensity, $R(\mathrm{~mm})$ & 100 & 100 & 100 & & \\
\hline Freeze-thaw action cycles & - & - & 1 & & \\
\hline $\begin{array}{l}\text { Other condition: } \\
\text { cyclic loading (gal), loading cycles }=20\end{array}$ & - & $200,280,550$ & - & & \\
\hline
\end{tabular}

Figure 6 (a) and (b) depicts a complete view of the apparatus used in the rainfall test and in the shaking table test. The soil container was $2,000 \mathrm{~mm}$ long, $700 \mathrm{~mm}$ deep, and $600 \mathrm{~mm}$ wide, and its front wall was made of 
reinforced glass to enable observation of deformation when failure occurred. In order to reveal the mechanical behavior of volcanic slopes subjected to pre-deformation due to cyclic loadings, a shaking table was also equipped in the soil container. The shaking table was $400 \mathrm{~mm}$ long, $450 \mathrm{~mm}$ deep, and $580 \mathrm{~mm}$ wide; its specifications are depicted in Table 5.

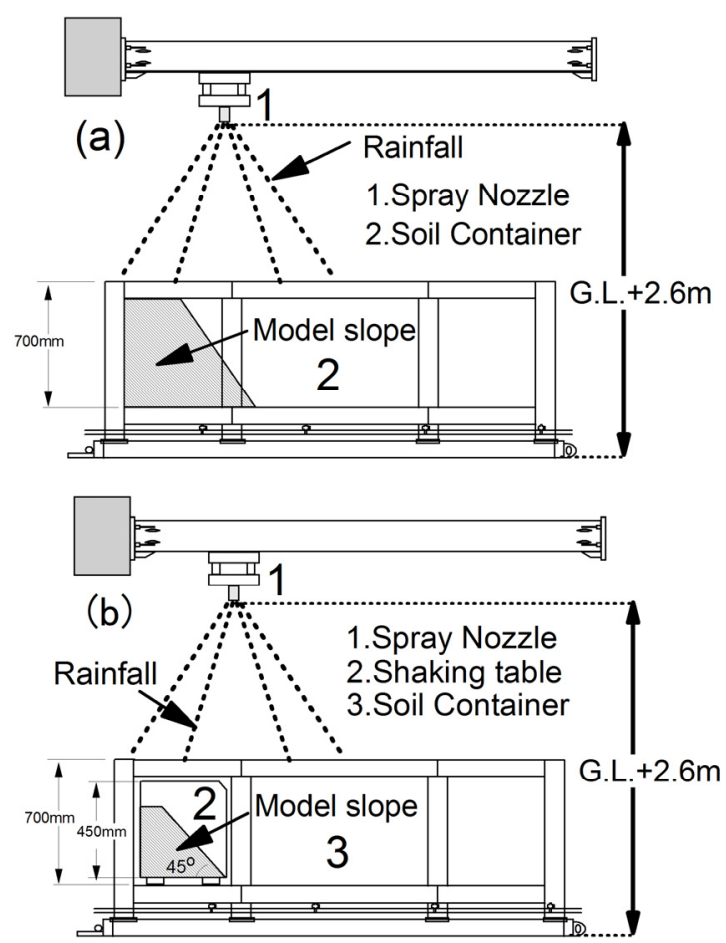

Figure 6. The whole view of apparatus: (a) rainfall- model test, (b) model test using a shaking table
Table 5. Specifications of shaking table

\begin{tabular}{lc}
\hline Maximum loading weight & $1500 \mathrm{~N}$ \\
Amplitude & $+/-50 \mathrm{~mm}$ \\
Frequency & $0.05 \sim 5 \mathrm{~Hz}$ \\
Wave & Regular wave \\
Control system & AC-Servo motor, Hydraulic control \\
\hline
\end{tabular}

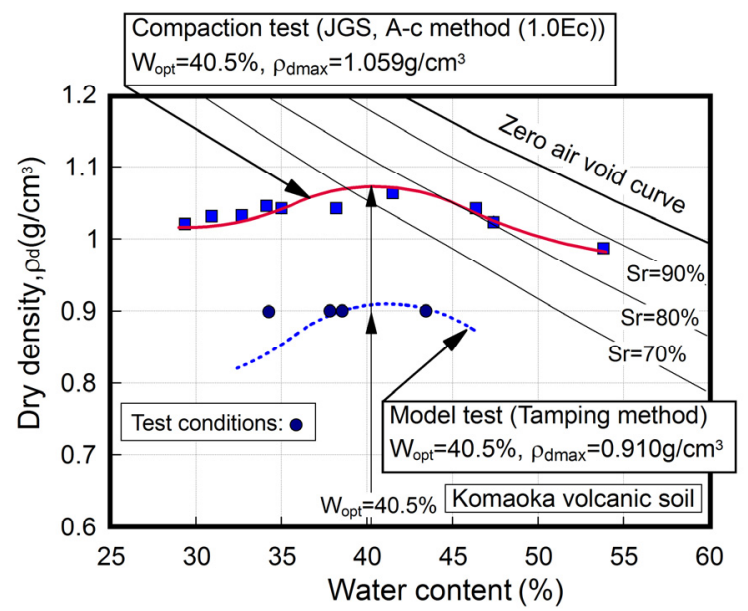

Figure 7. Compaction curves of Komaoka volcanic soil

Model slopes were constructed by compacting to attain the desired value (see Table 4, variations in dry density are within $5 \%$, respectively) where constituent particles were not broken by compaction under the initial water contents. The desired initial water content of the model slope $w_{0}$ is shown in Table 4. In particular, four kinds of water content $w_{0}=34 \%, 37 \%, 38 \%$, and $43 \%$ were adopted for the Komaoka volcanic soil to evaluate the difference in water content between the drier and wetter sides as the boundary of the optimum water content on slope failure. Figure 7 depicts compaction curves of the Komaoka volcanic soil which were obtained by the A-c method of JGS (2009) and by a tamping method for model tests. The weights of rollers used for compaction and the number of compactions are summarized in Table 6. In general, it is presumed that the compacted density varies with the change in water content if the same compaction energy is adopted. However, a change in density was not observed in this study. The reason for this is that the range between maximum and minimum densities is small for volcanic coarse grained soils.

Table 6. Weight of roller and number of compactions for each case

\begin{tabular}{lccccc}
\hline Sample name & $\begin{array}{c}\text { Desired dry density } \\
\left(\mathrm{g} / \mathrm{cm}^{3}\right)\end{array}$ & $\begin{array}{c}\text { Initial water content } \\
(\%)\end{array}$ & Weight of roller (N) & $\begin{array}{c}\text { Number of } \\
\text { compactions } \\
(\text { per 1layer })\end{array}$ & $\begin{array}{c}\text { Thickness of } \\
\text { compaction layer } \\
(\mathrm{mm})\end{array}$ \\
\hline Touhoro & 0.44 & $45,50,65,80$ & 29.4 & 20 & 100 \\
Komaoka & 0.90 & $34,37,38,43$ & 127.4 & 4 & 50 \\
Kashiwabara & 0.48 & $20,40,55,60,70$ & 29.4 & 1 & 100 \\
Nakayama & 1.2 & 25 & 127.4 & 1 & 100 \\
\hline
\end{tabular}


For all model testing, the difference in failure mechanism due to around $5 \%$ of variation in the initial degree of saturation for each position was not observed (Kawamura et al., 2010a). As a result, the variation in initial saturation was set within 5\%. Thereafter, the slope surface was carefully cut to the angles of 45,55 and $65 \mathrm{deg}$. (relative to horizontal) using a straight edge to eliminate surface disturbance. In order to appropriately simulate freezing and thawing actions, model slopes were constructed for Kashiawabara, Touhoro and Komaoka volcanic soils. The surface of the slopes was frozen with dry ice over eight hours and was then thawed at $20{ }^{\circ} \mathrm{C}$ (over a basic thawing period of eight hours). This is why the frost-heaving phenomenon was not sufficiently reproduced. The freeze-thaw phenomenon of the slope surface was intended in this study. According to this procedure, frozen layers of $25 \sim 80 \mathrm{~mm}$ in thickness were formed for Touhoro, Komaoka and Kashiwabara model slopes.

Rainfall intensity of 60,80 , or $100 \mathrm{~mm} / \mathrm{hr}$. was typically adopted and was accurately simulated using spray-nozzles. Figure 8 (a) and (b) shows typical slope shapes (65 and 45 deg. slopes) and the setting positions of measurement devices for rainfall testing and for both rainfall and cyclic loading testing ( 45 deg. slope), respectively. For 55 deg. slopes in rainfall tests, the measurements devices were basically set at the same positions as those of 45 and $65 \mathrm{deg}$. slopes (the depth from the slope surface and the elevation). For example, according to this model testing, the depths of measurement devices in the real field can be converted by multiplying those in the model by $\lambda$ times for rainfall model tests, as shown in Table 2 .

(a)

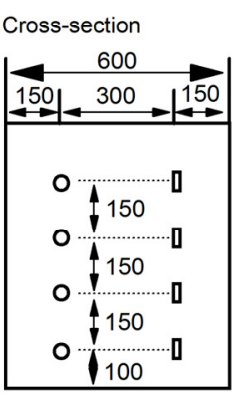

a) Non freeze-thaw action b) Freeze-thaw action
65 degree slope

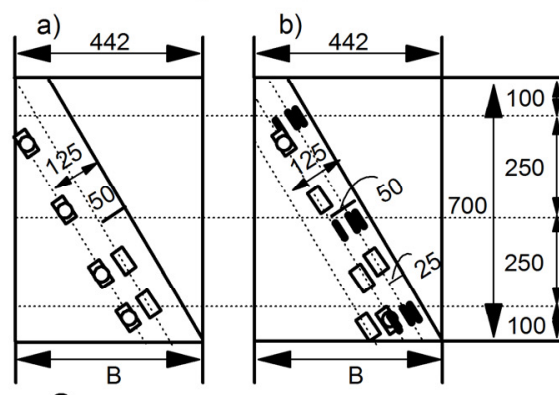

$\begin{array}{ll}\text { Pore water pressure transducer : pw } & \\ & \text { Soil-moisture meter : sm } \\ \text { Thermometer : } \mathrm{T} & \text { unit : } \mathbf{m m}\end{array}$

(b)

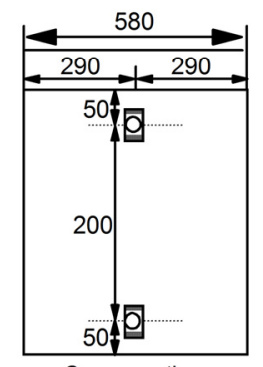

Cross-section

Acceleration meter: am

Soil-moisture meter : sm
45 degree slope
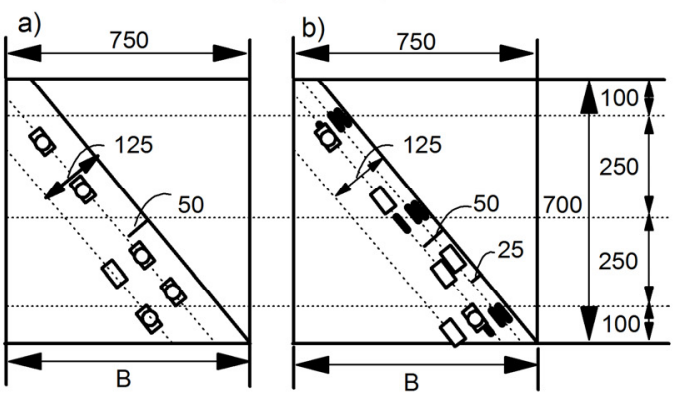

Figure 8. Typical model shapes (65 and $45 \mathrm{deg}$. slopes) and the setting positions of measurement devices: (a) rainfall model test, (b) model test using a shaking table

For the cases of volcanic model slopes using a shaking table, after the desired shearing deformations (shear strain, $\gamma=1 \%, 2 \%, 3 \%, 4 \%$, and $6 \%$ ) for model slopes of $w_{0}=37 \%$ generated by cyclic loading of 200 gal, 280 gal, or $550 \mathrm{gal}$, a series of rainfall model tests was conducted. The same input-accelerations as those for $w_{0}=37 \%$ were adopted as cyclic loads for model slopes of $w_{0}=43 \%$. The number of cycles was 20 times for all tests.

The rainfall from the slope bottom was mandatorily drained by a pump. Thereafter, the mechanical behavior of slopes subjected to seepage water was examined. During the rainfall test, changes in deformation behavior, 
saturation degree and temperature were monitored using digital video cameras, soil moisture meters and thermocouple sensors, respectively. Additionally, the deformation behavior was estimated according to particle image velocimetry (PIV) analysis (White, Take, \& Bolton, 2003). Soil moisture meters were calibrated on several density conditions of slopes. However, variations in soil moistures attributed to dilatancy induced by deformation of slopes during model tests were not evaluated in the subsequent discussion due to the difficulty in defining their behavior.

Pore water pressure was monitored simultaneously. In a series of model tests, negative pore water pressure due to suction exhibited small values. On account of this, the influence of the dissipation of suction on slope instability was ignored (Kawamura et al., 2010a). This fact has also been confirmed by triaxial compression tests which revealed the effect of the decrease in suction on the shear strength of volcanic soils (Ishikawa, Miura, \& Ito, 2010). In the subsequent examination, pore water pressure normalized by over burden pressure was used as a parameter due to the conventional $1 \mathrm{~g}$ model testing approach.

In previous studies, the relative relations between saturation degree, pore water pressure, and deformation prior to failure were also demonstrated on the basis of the preliminary test data on Toyoura sand and volcanic slopes (Kawamura et al., 2010a; Kawamura \& Miura, 2013). As a result, slope failure characterized by large deformation developed rapidly after a shear strain of 4-6\%. A similar tendency was obtained for the other volcanic soils. For these reasons, mechanical behavior at a shear strain of $4-6 \%$ by PIV analysis was regarded as that of the plastic equilibrium state, specifically that at failure. On the other hand, because it was difficult to estimate shear strain in a shaking table through PIV analysis, mechanical behavior at a shear strain of $6 \%$, as estimated by the deformations of seven strings of a kite, was defined as failure for the case of model tests carried out with the shaking table. According to the test procedure, the rainfall model testing was performed until slope failure was induced.

\section{Test Results and Discussions}

Before commencing discussion on the failure patterns of volcanic slopes subjected to freeze-thaw actions and cyclic loadings, the dependency of initial water content on failure caused by rainfall, which was investigated in earlier studies (Kawamura \& Miura, 2013; 2014), will be expanded upon to include several types of volcanic slopes.

\subsection{Slope Failure Due to Rainfall}

Photograph 1 and 2 illustrates typical states of failed shapes for Kashiwabara and Touhoro volcanic soils, where the initial water contents are $w_{0}=70 \%$ and $40 \%$ for Kashiwabara volcanic soil (65 deg. slope), and $w_{0}=80 \%$ and $45 \%$ for Touhoro volcanic soils (55 deg. slope), respectively (see Case 1 and Case 3). As shown in these photographs, the shapes of failed slopes are different for each type of volcanic slope. In particular, the slopes with lower water content fail at a shallower depth than those with higher water content.

Changes in saturation degree normalized by the initial value $S_{r 0}$ for Touhoro and Kashiwabara volcanic slopes (65 deg. slope) are shown in Figure 9 (a) and (b). In these figures, the data of sm1 which is placed around the slip line is typically depicted. As shown in the figures, the changes in elapsed time and in magnitude of saturation degree attributed to the difference in $w_{0}$ are recognized for each soil. For example, each value of elapsed time is at $180 \mathrm{sec}$. for $20 \%$, at $760 \mathrm{sec}$. for $40 \%$, and at $860 \mathrm{sec}$. for $70 \%$ in Kashiwabara volcanic soil. In the case of lower water content, seepage water due to rainfall can be retained in voids in the slope because its velocity becomes slower. As a result, surface slope failure rapidly occurs due to the increase of self-weight around shallower areas in Kashiwabara volcanic slopes (Kawamura et al., 2010a). Ishikawa, Miura and Tokoro (2009) have revealed the unsaturated mechanical behavior of Kashiwabara volcanic soil using element test devices. According to their research, the permeability of volcanic soil decreased when the saturation degree was less than around $60 \%$.

On the other hand, the changes in elapsed time and in the magnitude of saturation degree for Touhoro volcanic soil are different from those of Kashiwabara volcanic soil (see Figure 9 (a)). The reason for this is that Touhoro volcanic soil has a high ability to retain water due to the soil particles being more porous and crushable compared to Kashiwabara volcanic soil (Nakata \& Miura, 2006). This indicates that the depth of the slip line and failure modes change depending on the increase of water retention capacity with seepage for such volcanic soils. 


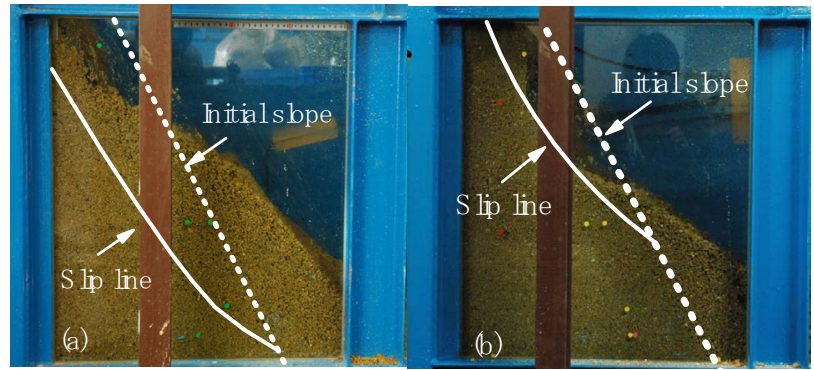

Photograph 1. Typical shape of failed slope for Kashiwabara volcanic soil: (a) $w_{0}=70 \%$, (b) $w_{0}=40 \%$
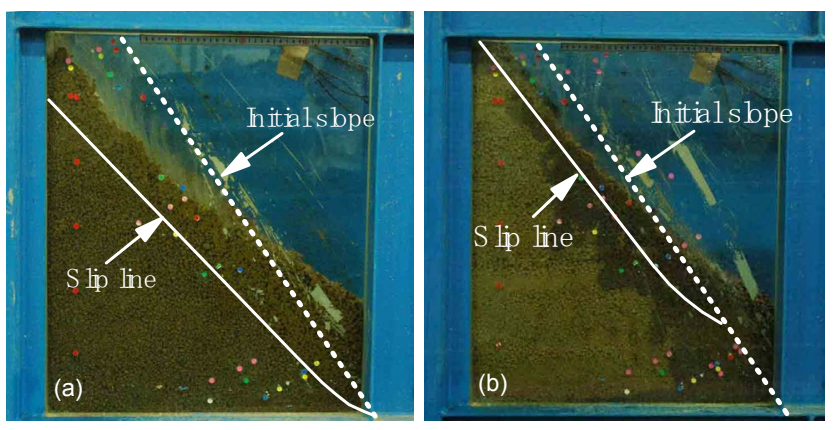

Photograph 2. Typical shape of failed slope for Touhoro volcanic soil: (a) $w_{0}=80 \%$, (b) $w_{0}=45 \%$
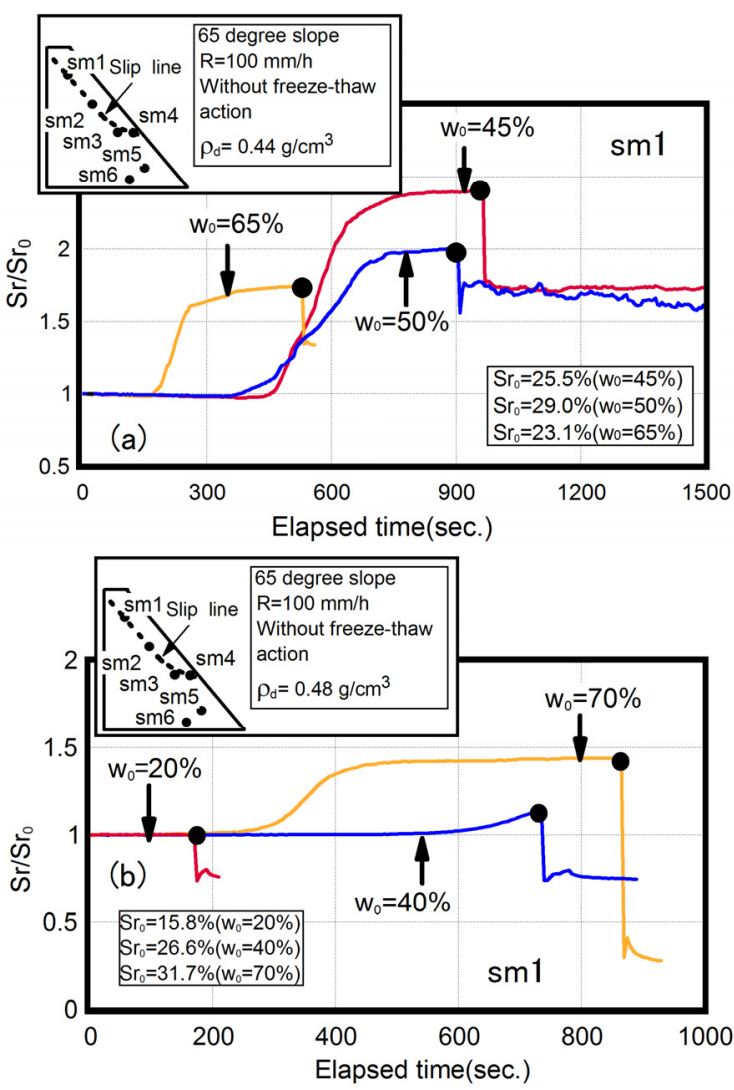

Figure 9. Typical changes in saturation degree (sm1) until failure: (a) Touhoro volcanic slope, (b)

Kashiwabara volcanic slope

In comparison with the typical behavior of pore water pressure normalized by the initial effective overburden pressure $\sigma_{v 0}$ in the cases of $w_{0}=45 \%$ and $65 \%$ for the Touhoro volcanic slope ( 65 deg. slope, see Figure 10 (a) and (b)), the pore water pressure around the slip line gradually increased until failure; however, its behavior is not sensitive compared with that of the degree of saturation (see Figure 9(a)). For this reason, it is important to monitor changes in water content to predict slope failure. A similar tendency was obtained in previous research (Kawamura \& Miura, 2013). The failure phenomenon was similarly observed in the behavior of full-scale embankments constructed by the same soil material, and was also illustrated using three-dimensional analysis taking distributions and changes of water contents into account (Kawamura \& Miura, 2014; Fukutsu, Kawamura, \& Miura, 2014).
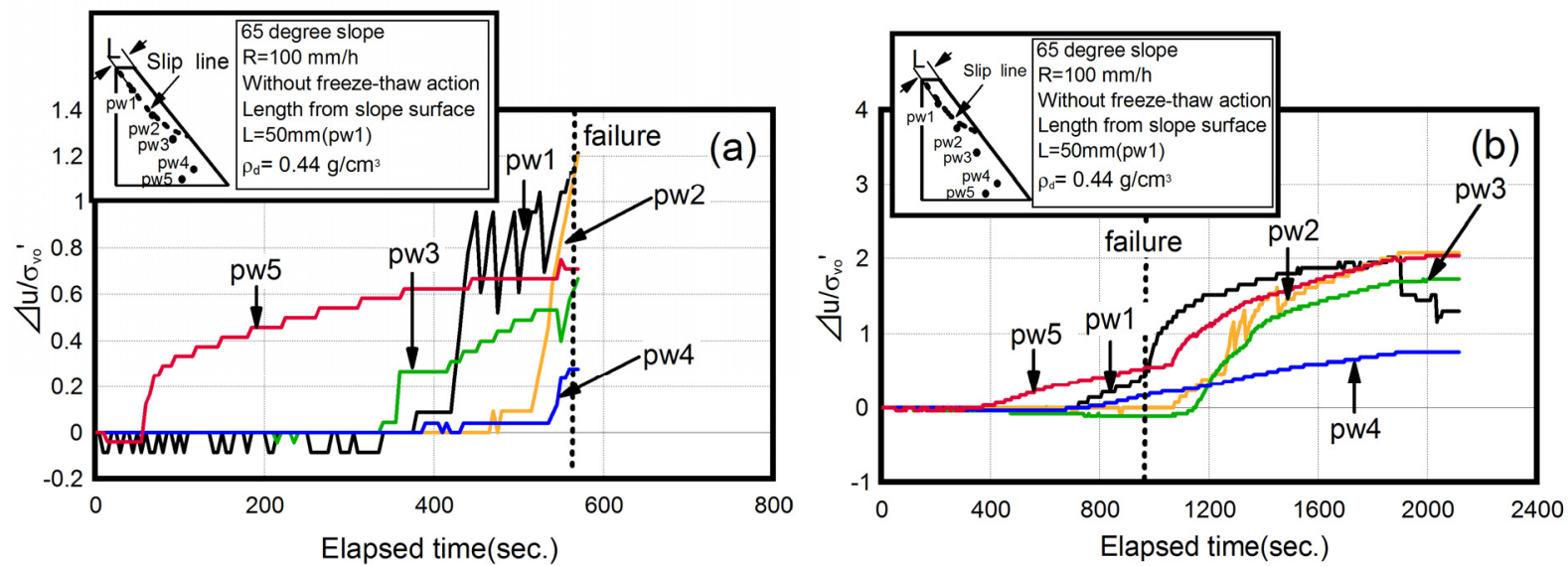

Figure 10. Typical changes in pore water pressure until failure for Touhoro volcanic slope: (a) $w_{0}=65 \%$, (b) $w_{0}=$ $45 \%$ 
Photograph 3 and Figure 11 illustrates typical failed shapes and distributions of shear strain at slope failure for Komaoka volcanic soils (see Case 6). For the cases of lower water contents of $w_{0}=34 \%$ and $38 \%$, it is found that the first failure (Slip line 1) is generated at the toe of slopes, and then the second failure (Slip line 2, circular failure) is rapidly induced with an increase of pore water pressure. On the other hand, slope failure with circular slip is not confirmed for the case of high water content of $w_{0}=43 \%$. Surface flow with gully erosion proceeded until the Slip line indicated in Photograph 3 (c) for the case of high water content, and the elapsed time was 9,000 sec. (see Photograph $3(\mathrm{~d})$ ) when the model test was continued until the same depth as the slip line 2 for $w_{0}=34 \%$ and $38 \%$ (see Figure 11(a) and (b)). As shown in Figure 7, it is clarified that the optimum water content is $40.5 \%$ in compaction curves. The difference in failure mode is also obvious from the changes in the development of saturation degree and in excess pore water pressure (see Figure 12 (a) and (b), Figure 13 (a) and (b)). For instance, pore water pressure for $w_{0}=38 \%$ is suddenly developed compared with that for $w_{0}=43 \%$. Owing to the difference in the initial water content, slope failure with circular slip line is induced for $w_{0}=34 \%$ and $38 \%$, and surface flow is generated for the case of $w_{0}=43 \%$ because the permeability generally decreases for higher water content over the optimum water content.
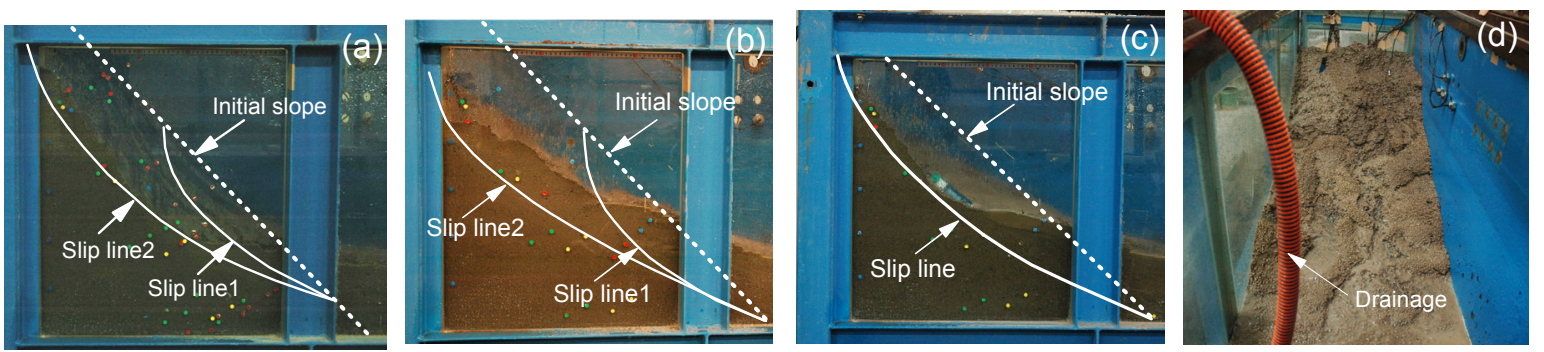

Photograph 3. Failed shapes of Komaoka volcanic slopes: (a) $w_{0}=34 \%$ (side view), (b) $w_{0}=38 \%$ (side view), (c) $w_{0}=43 \%$ (side view), (d) $w_{0}=43 \%$ (cross view)
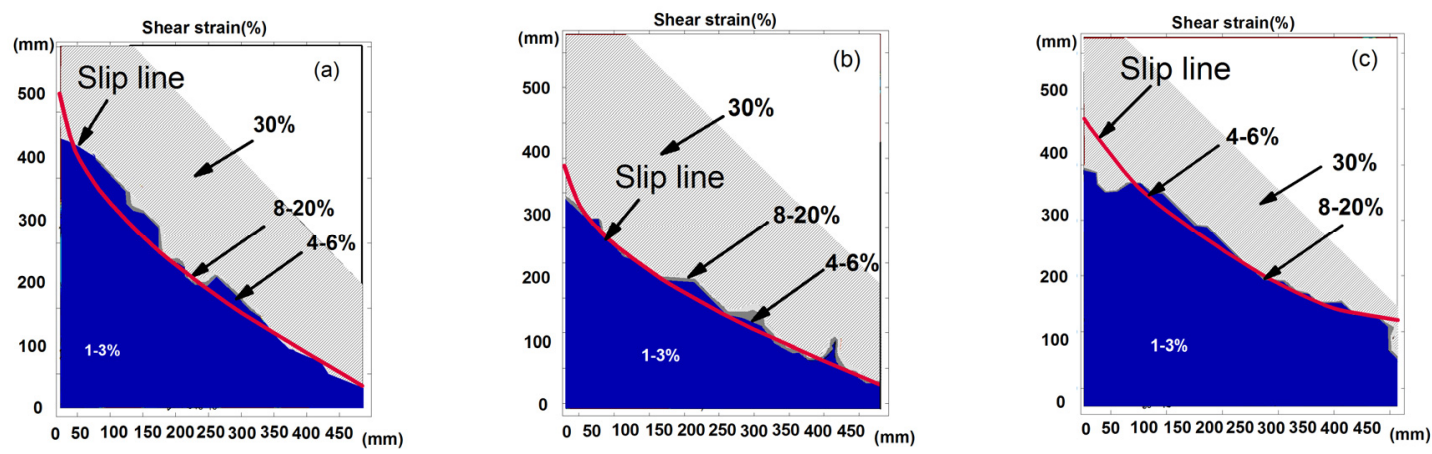

Figure 11. Deformation behavior (shear strain) at failure for Komaoka volcanic slope (PIV analysis): (a) $w_{0}=34 \%$, (b) $w_{0}=38 \%$, (c) $w_{0}=43 \%$
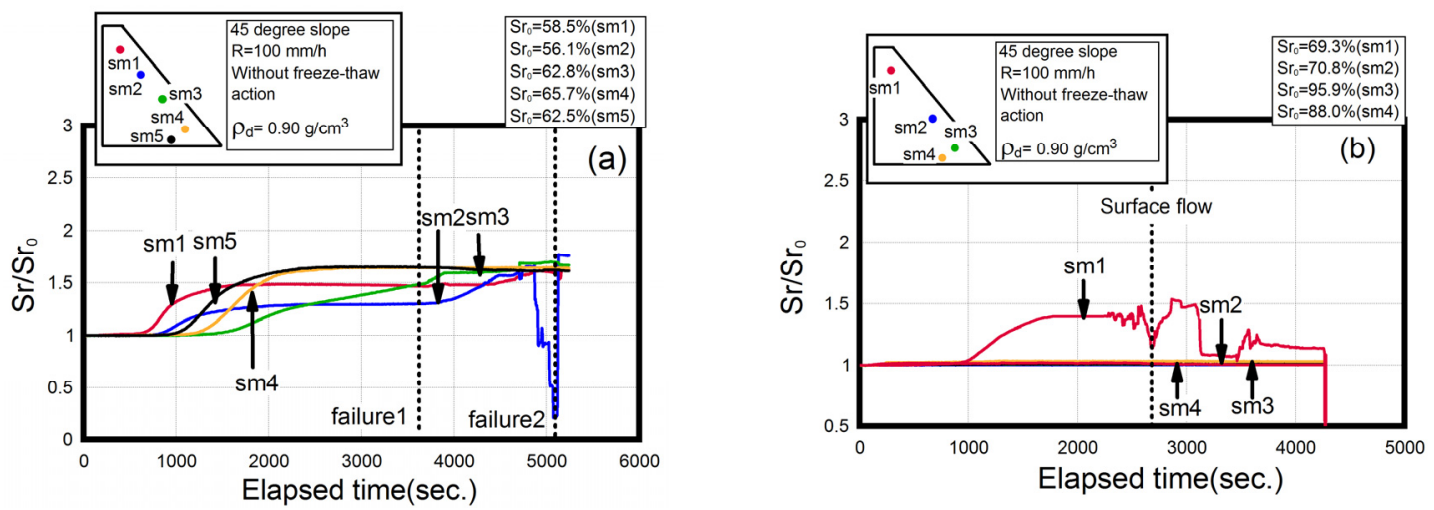

Figure 12. Changes in the degree of saturation during model test: (a) $w_{0}=38 \%$, (b) $w_{0}=43 \%$ 

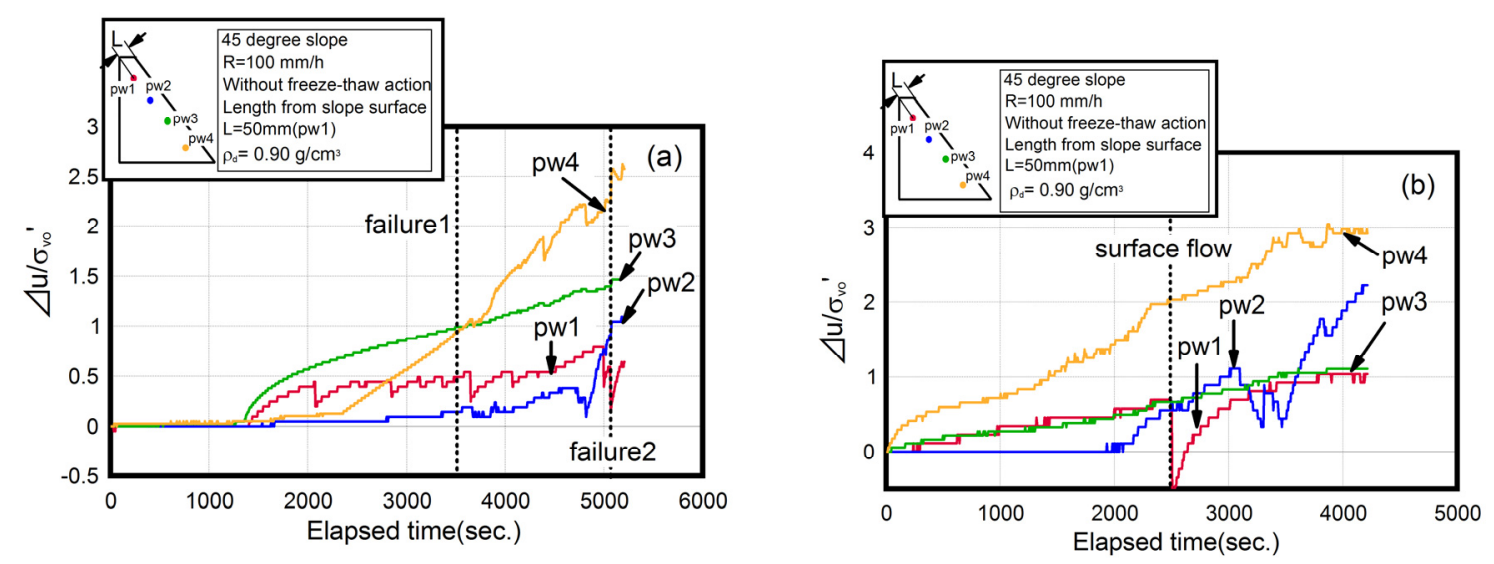

Figure 13. Changes in pore water pressure during model test: (a) $w_{0}=38 \%$, (b) $w_{0}=43 \%$

Similarly, surface failure of Nakayama volcanic slopes due to an increase of pore water pressure and saturation degree was also observed despite a difference in rainfall intensity (see Case 5), as shown in failed shapes (Photograph 4) and the developments of pore water pressure and saturation degree (see Figure 14).

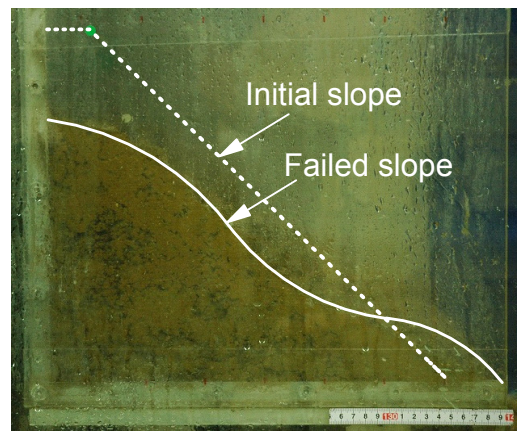

Photograph 4. Typical failed shape of Nakayama volcanic slope under $\mathrm{R}=60 \mathrm{~mm} / \mathrm{hr}$
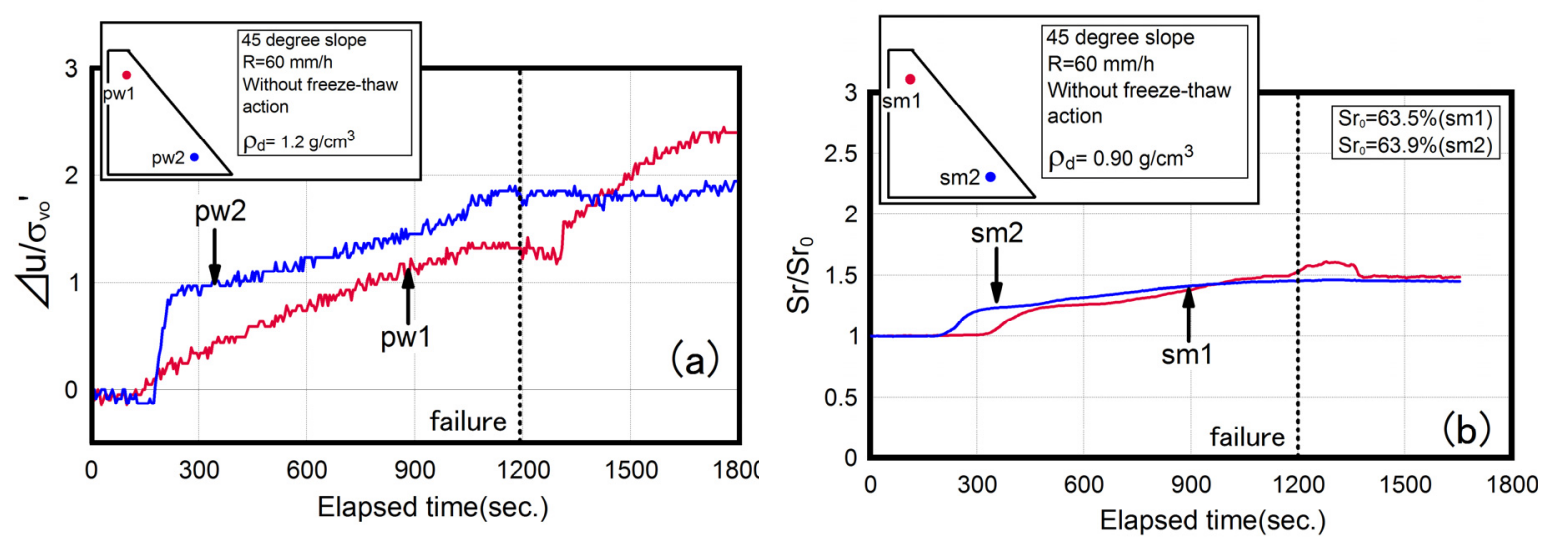

Figure 14. Changes in pore water pressure and the degree of saturation for Nakayama volcanic soil: (a) pore water pressure, (b) degree of saturation

As mentioned above, the difference in development of the degree of saturation due to an increase of pore water pressure and seepage force is one of the causes of slope failure. More specifically, slope failures appear to be induced by the expansion of areas with high water retention. Presented herein is a prediction method for slope failure of such volcanic slopes which takes into account water retention characteristics. Based on the results of all test data, the relationships between water content at the initial $w_{0}$ and at the failure $w_{f}$ are shown in Figure 15. In 
this figure, test data for freeze-thaw actions and cyclic loadings, which will be described in subsequent discussion, are also depicted (see Case 2 and Case 4, Case 7 and Case 8). The water retention capacity was calculated as water content. This figure demonstrates that there are unique relationships between both water contents when large deformation is induced in slopes. In particular, note that the ratio of the increase of water content becomes a constant with the increase of initial water content. For instance, the following expression can be obtained;

$$
w_{f}=\beta w_{0}^{\gamma}
$$

where $\beta$ and $\gamma$ are coefficients (these values are shown in Table 7). As shown in the table, it is interesting that there is no difference in $\gamma$ among these volcanic soils and that the $\beta$ of the Kashiwabara and Komaoka volcanic soils, which were sampled from the same volcano ejecta, demonstrated the same value. This may indicate that the features of seepage and water retention capacity depend on the ejecta of particular volcanos and can be evaluated uniquely. The test data for Nakayama volcanic soil is also on the line near the sites of Komaoka and Kashiwabara areas. Additionally, it has been clarified that water content at failure indicates the liquid limit of the other slope covered by silty soils (Kaiya, Kawamura, \& Miura, 2013). The validity of the proposed method was also confirmed on the behavior of full scale embankments formed by Komaoka volcanic soils (Kawamura \& Miura, 2014). Therefore, the proposed method will be available in practice.

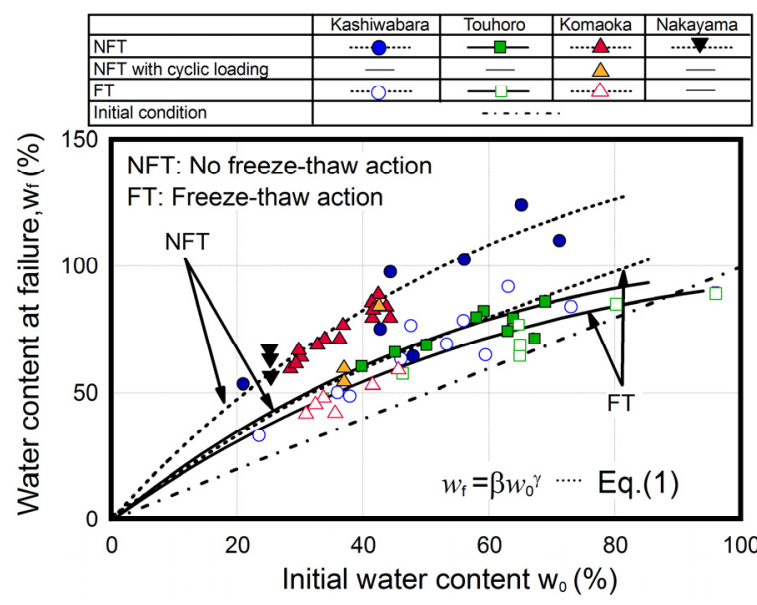

Table 7. Coefficients of $\beta$ and $\gamma$

\begin{tabular}{lcccccccc}
\hline & \multicolumn{2}{c}{ Kashiwabara } & \multicolumn{2}{c}{ Komaoka } & \multicolumn{2}{c}{ Nakayama } & \multicolumn{2}{c}{ Touhoro } \\
\cline { 2 - 9 } & $\beta$ & $\gamma$ & $\beta$ & $\gamma$ & $\beta$ & $\gamma$ & $\beta$ & $\gamma$ \\
\hline NFT & 2.4 & 0.9 & 2.4 & 0.9 & 2.4 & 0.9 & 4.3 & 0.7 \\
NFT-CL $\left(w_{0}=37 \%\right)$ & - & - & 2.8 & 0.8 & - & - & - & - \\
NFT-CL $\left(w_{0}=43 \%\right)$ & - & - & 2.4 & 0.9 & - & - & - & - \\
FT & 2.8 & 0.8 & 2.8 & 0.8 & - & - & 2.4 & 0.8 \\
\hline
\end{tabular}

NFT: No freeze-thaw action, FT: Freeze-thaw action

NFT-CL: No freeze-thaw action with cyclic loadings

Figure 15. Relationship between water content at initial and at failure for each volcanic soil

For example, slope stability can be evaluated in practice according to the following procedure, based on Figure 15 and Equation (1).

(1) Estimate the line of water content, $w_{f}$ which may cause slope failure.

(2) Investigate the initial water content at the setting positions of measurement instruments such as soil moisture meters.

(3) Monitor the change in water content due to the increase of rainfall or snowmelt water.

(4) If the monitoring data of water content reaches the predicted line shown in Equation (1), the destabilization

(failure) of the slope will be predicted.

(5) Finally, evaluate slope stability by taking the geometric conditions of slopes into account.

In this way, it is possible to evaluate slope stability if such a relation can be obtained for an in-situ slope, and slope failure can be predicted if the water retention capacity in a slope is estimated by monitoring an index property such as water content.

\subsection{Rainfall-induced Failures of Volcanic Slopes Subjected to Freezing and Thawing}

On the basis of the above test results, a series of rainfall model tests with freeze-thaw action were carried out. For the model test on model slopes subjected to freeze-thaw action, the surface of the slope was frozen with dry ice over a period of eight hours, and was thawed at a temperature of $20{ }^{\circ} \mathrm{C}$ over eight hours after the model slope was constructed; thereafter, a rainfall test was performed until failure. Typical changes in temperature (T1-T9) in model slopes during freeze-thaw action for each material are depicted in Figure 16 (a), (b) and (c). As shown in 
these figures, temperatures decrease during freezing action (until around 28,800 sec.), and thereafter increase with the elapsed time. In particular, the values at the depth of $25 \mathrm{~mm}$ (T1, T4 and T7) are less than approximately $0{ }^{\circ} \mathrm{C}$ although changes in temperatures differ for each soil.
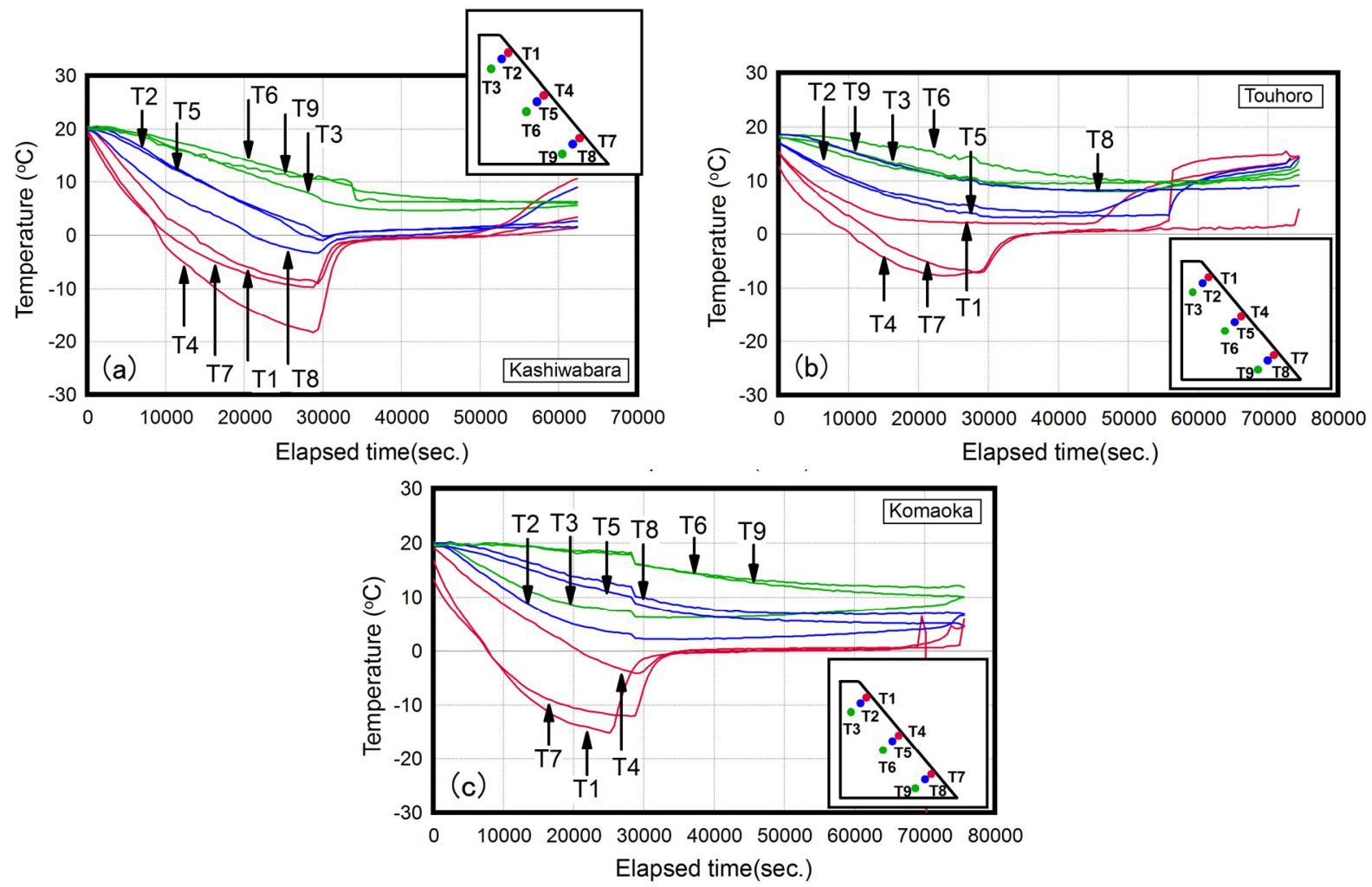

Figure 16. Typical changes in temperature during freeze-thaw action: (a) Kashiwabara volcanic soil, (b) Touhoro volcanic soil, (c) Komaoka volcanic soil

Figure 17 (a) and (b) shows the changes in the normalized degree of saturation during rainfall tests after freeze-thaw action for Kashiwabara volcanic soil, compared to that without freeze-thaw action (see Case 3 and Case 4). It can be seen that $S r_{0}$ at sm6 indicates a high value (see Figure 17 (b)). The reason for this was that sm6 was set to $15 \mathrm{~mm}$ from the bottom and its area became highly saturated due to the effect of seepage water. Each degree of saturation gradually increases, and then suddenly decreases after failure (see the black symbol). It is also noted that there is a difference in elapsed time before failure between both cases. For example, the elapsed time subjected to freeze-thaw action (105 sec.) is around 9 times faster than that without $(876 \mathrm{sec}$.$) .$
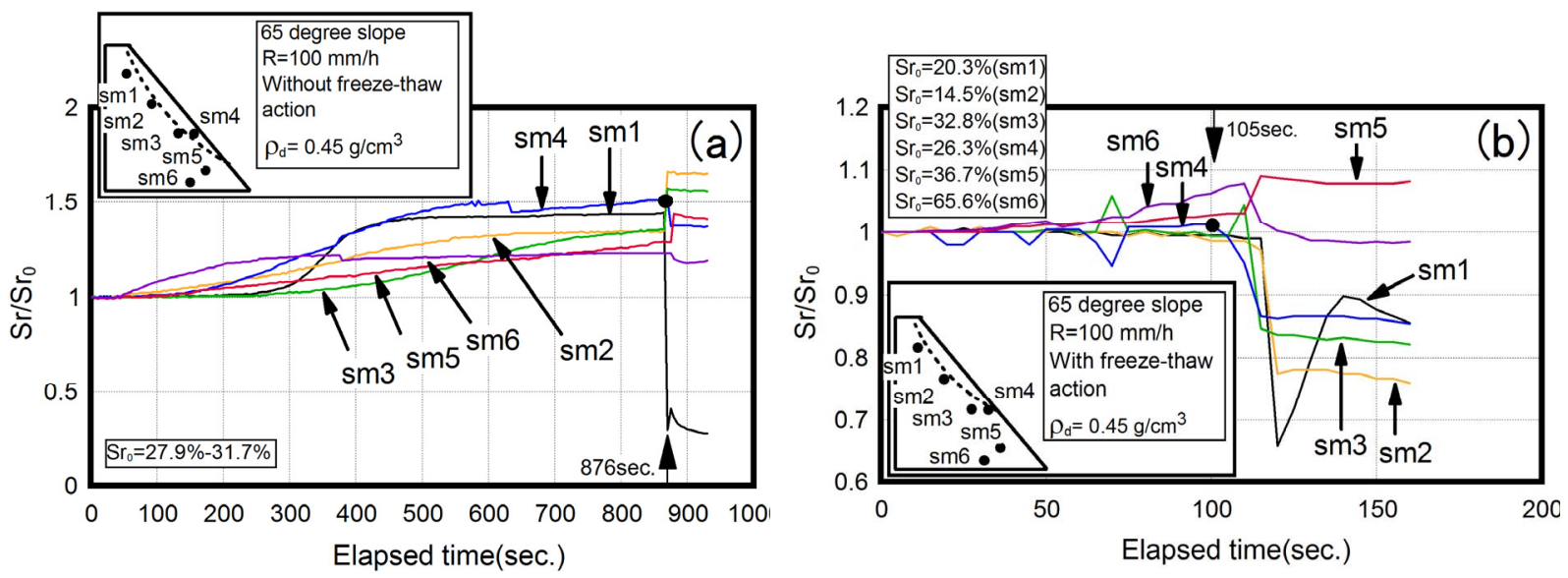

Figure 17. Changes in saturation degree during rainfall test for Kashiwabara volcanic slope ( $\left.w_{0}=70 \%\right)$ : (a) no freeze-thaw action, (b) freeze-thaw action 
The typical changes in degree of saturation for Komaoka and Touhoro volcanic soils are shown in Figure 18 (Case 2 and Case 8). In comparison with the no freeze-thaw action for Komaoka volcanic soil (see Figure 12 (b) and Figure18 (a)), it was found that there is no difference in the development of saturation between both cases, but the difference in elapsed time until failure is apparently confirmed. For example, the elapsed time subjected to freeze-thaw action is $765 \mathrm{sec}$. which is around 3.5 times faster than that without $(2,690 \mathrm{sec}$.). A similar tendency was obtained from the data for Touhoro volcanic soil (see Figure 9 (a) and Figure 18 (b)). Ishikawa, Miura and Tokoro (2009) have also revealed the effect of freeze-thaw action on hydraulic behavior of Kashiwabara volcanic soil subjected to freeze-thaw action using element test devices. Their results clarified that the coefficient of permeability of freeze-thawed specimens decreased in comparison with that of non freeze-thawed specimens under the same degree of saturation. This appears to be because of the realignment of constituent particles of volcanic soil caused by freezing and thawing. Therefore, this fact appears to explain the above results well.
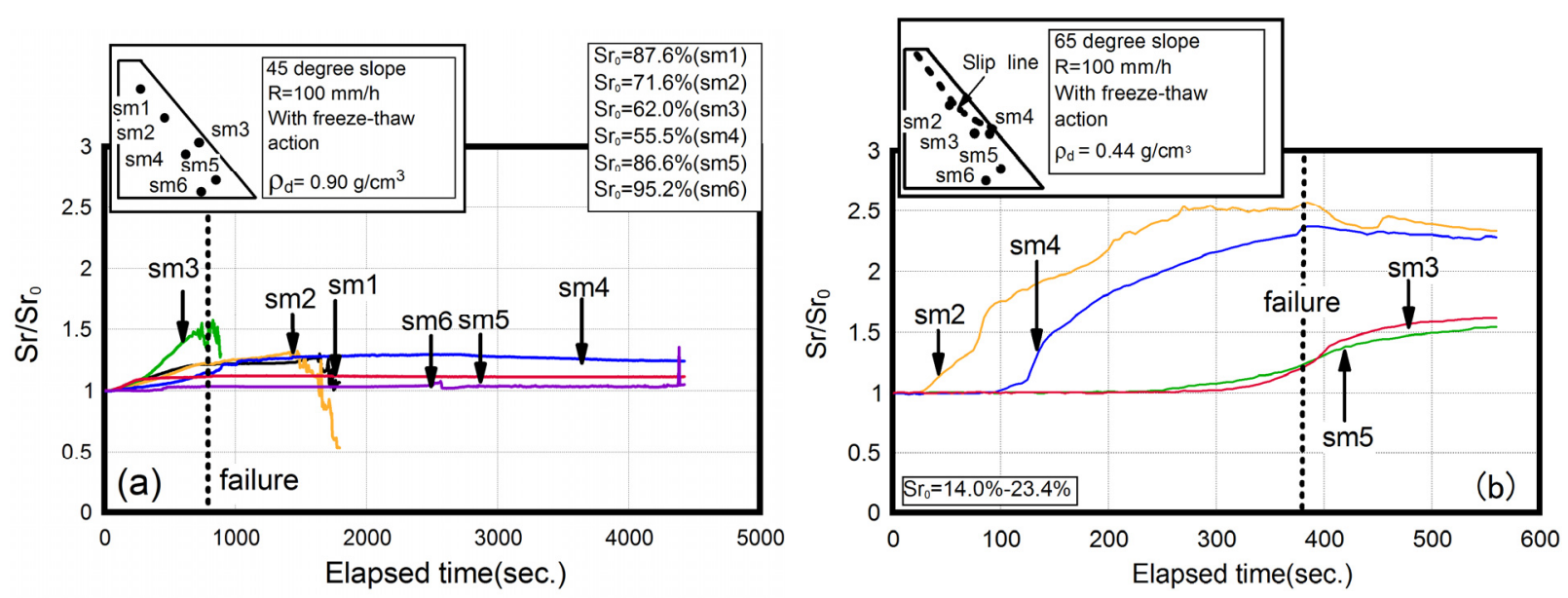

Figure18. Changes in saturation degree for freeze-thaw action: (a) Komaoka volcanic slope $\left(w_{0}=43 \%\right)$, (b) Touhoro volcanic slope $\left(w_{0}=45 \%\right)$

In order to clarify the influence of freeze-thaw action on the deformation behavior of model slopes, Figures 19 , 20, 21 and 22 illustrate the deformation behavior (the distributions of shear strain) with freeze-thaw action for Kashiwabara, Touhoro, and Komaoka volcanic soils, respectively. In Figure 19, deformation vectors are also indicated for Kashiwabara volcanic soil. As Figures 19 and 20 demonstrate, the shear strain increases with freezing and becomes a constant value during thawing and its zone is almost the same as the depth of slip line. The typical deformation vectors are approximately perpendicular to the surface during freezing action, and its direction changes due to gravity during thawing action. The variation in density can also be confirmed, as shown in the inserted photograph in Figure 19. For comparison of those for non freeze-thaw action (see Figure 21 (a) and (b), Figure 11 (b), (c) and Figure 22 (a), (b)) for Touhoro and Komaoka volcanic slopes, it is apparent that there is a difference in the shape at the final slip line between both cases. For example, the depth of the slip line with freeze-thaw action is shallower than that without freeze-thaw action. This fact indicates that hollows caused by thawing generate loose structures in the frozen layer compared with before the freeze-thaw process (as shown in Figure 1 (d)). The differences in deformation behavior due to the change in the initial water content were also not recognized for the other volcanic slopes subjected to freezing and thawing. A similar tendency was also observed in field monitoring data on a cut slope in Hokkaido, Japan (Kawamura \& Miura, 2011). 


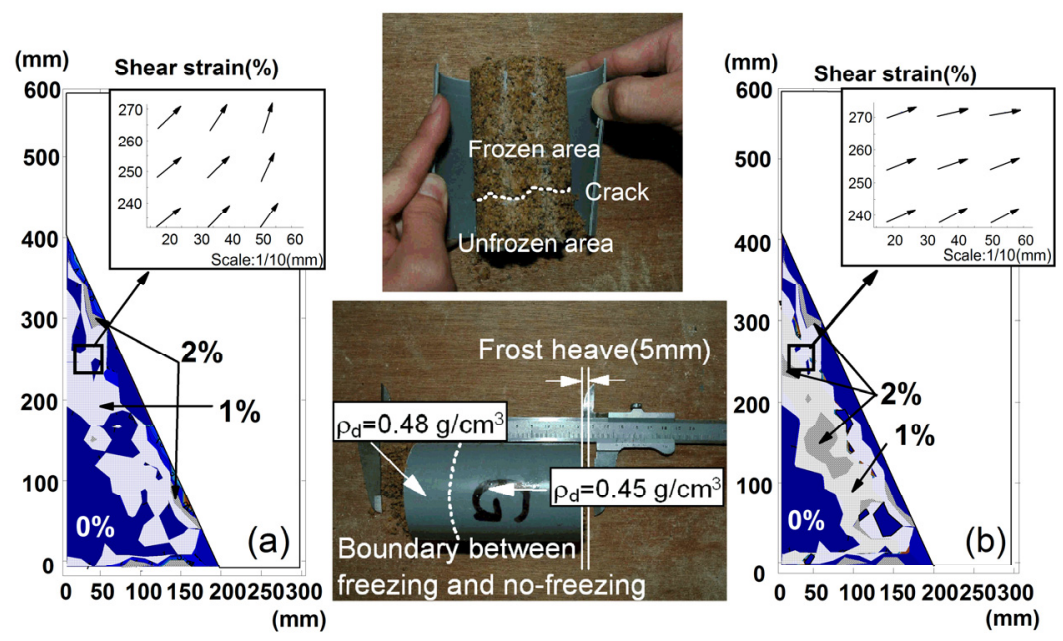

Figure 19. Deformation behavior (shear strain) of volcanic slope for Kashiwabara volcanic slope (PIV analysis):

(a) freezing action, (b) thawing action

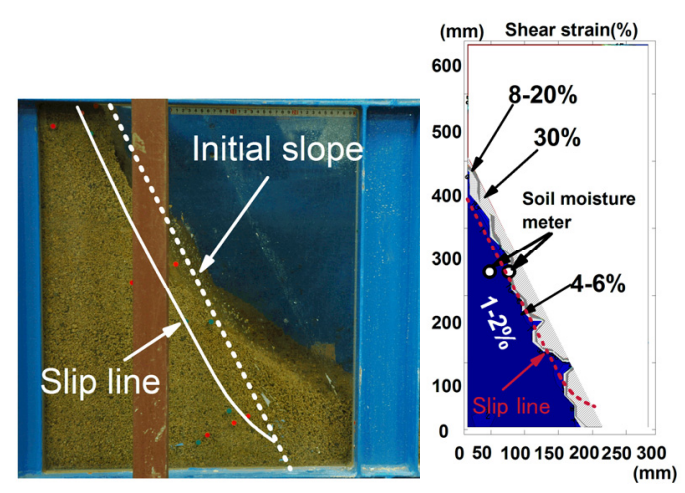

Figure 20. Deformation behavior (shear strain) at failure for Kashiwabara volcanic slope
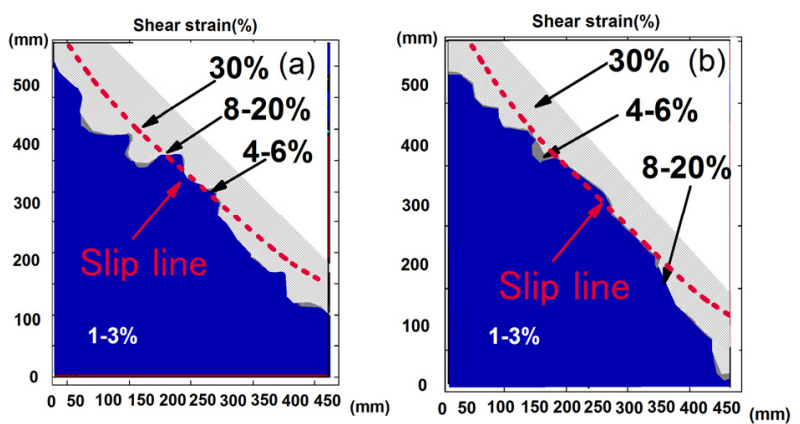

Figure 22. Deformation behavior (shear strain) at failure for Komaoka volcanic slope subjected to freeze-thaw action: (a) $w_{0}=38 \%$, (b) $w_{0}=43 \%$
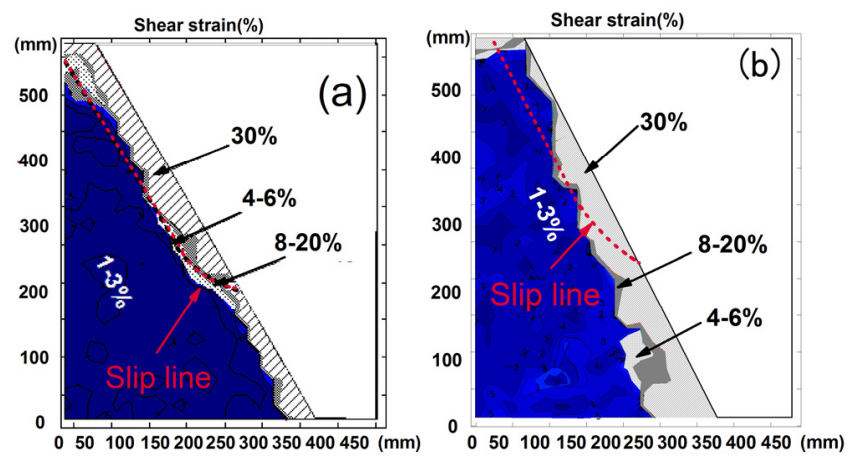

Figure 21. Deformation behavior (shear strain) at failure for Touhoro volcanic slope: (a) no freeze-thaw action, (b) freeze-thaw action

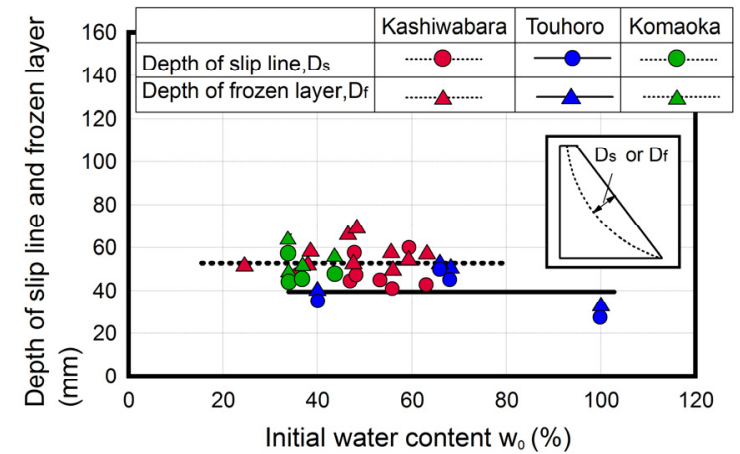

Figure 23. Comparison of the depths of slip line $D_{\mathrm{s}}$ with frozen layer $D_{\mathrm{f}}$ after rainfall test

To examine this behavior further, comparisons of the depths of the slip line $D$ s, and of the frozen layer $D_{\mathrm{f}}$, observed in the model test are shown in Figure 23. This figure demonstrates that the depth is almost the same for each case. From these results, it can be said that such volcanic slopes subjected to freezing and thawing actions have already been in the plastic equilibrium state. Therefore, the influence of freeze-thaw action on surface failure 
of volcanic slopes can be evaluated accurately if the depth of frozen areas for in-situ slopes can be estimated by field monitoring devices.

As previously discussed, the influence on failure mechanisms was characterized by natural events such as rainfall, freezing, and thawing. Similarly, the effects of material characteristics of soils were investigated, for instance, the particle breakages of volcanic soils during model testing. Figure 24 illustrates the increment of finer content before and after tests $\Delta F \mathrm{c}(\%)$, for each type of volcanic soil. $\Delta F \mathrm{c}$ increases with the increase of initial water content. It is interesting that particle breakage increases with stress histories such as rainfall and freeze-thaw action. This implies that failures of unsaturated volcanic slopes with crushable particles are derived not only by loose structures due to freeze-thaw actions, but also the reduction of shearing resistance due to particle breakage during rainfall and freeze-thaw action. The reduction of shearing resistance due to particle breakage was described by Miura, Yagi and Kawamura (1996) and Yagi and Miura (2004). Accurate estimation of the softening of slope surfaces by freeze-thaw action is important for the stability of volcanic slopes; in particular, its influence is attributed to the reduction of shearing resistance due to particle breakage.

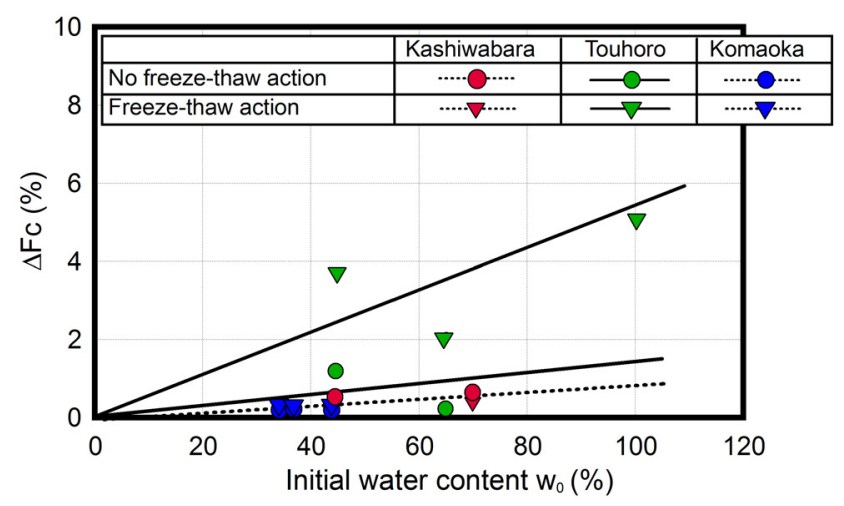

Figure 24. Changes in the increment of finer content $\Delta F \mathrm{c}$ after rainfall test

\subsection{Rainfall-induced Failures of Volcanic Slopes Subjected to Cyclic Loadings}

In order to identify mechanical behavior during rainfall for volcanic slopes subjected to cyclic loadings, a series of model tests using a shaking table was conducted for Komaoka volcanic slopes (see Case 7). Firstly, fundamentals of mechanical behavior of volcanic slopes during cyclic loadings were investigated under two kinds of initial water content. In preliminary tests, slope failure was induced by cyclic loadings of 550 gal for each water content.

Photograph 5 (a) and (b) shows typical slope shape after cyclic loadings of 280 gal for each water content. Shear strain induced for $w_{0}=37 \%$ and $43 \%$ was $\gamma=2.8 \%$ and $1.6 \%$, and vertical strain $\varepsilon_{\mathrm{v}}$ (ratio of settlement of crown/the initial height) was $1 \%$ and $0.4 \%$, respectively. Figure 25 (a) and (b) illustrates variation of acceleration at basement and crown, compared with that of the shaking table. As shown in Figure 25, the maximum acceleration at the crown of the slope (A point) for both cases is larger than those at other points (B and C points), and its tendency is significant for $w_{0}=43 \%$.
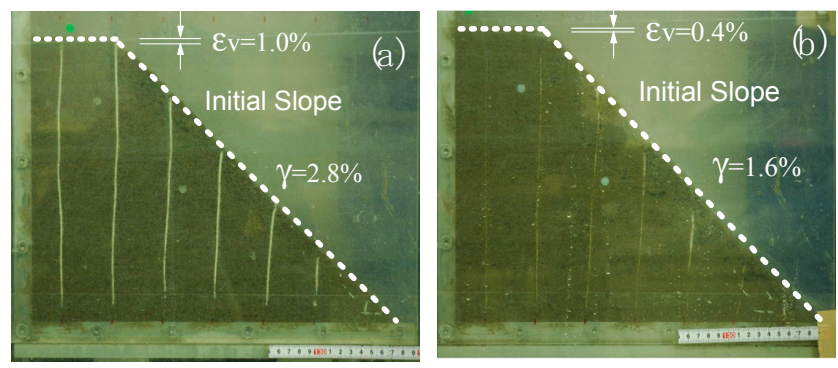

Photograph 5. Slope shape after cyclic loadings of 280gal: (a) $w_{0}=37 \%$, (b) $w_{0}=43 \%$ 

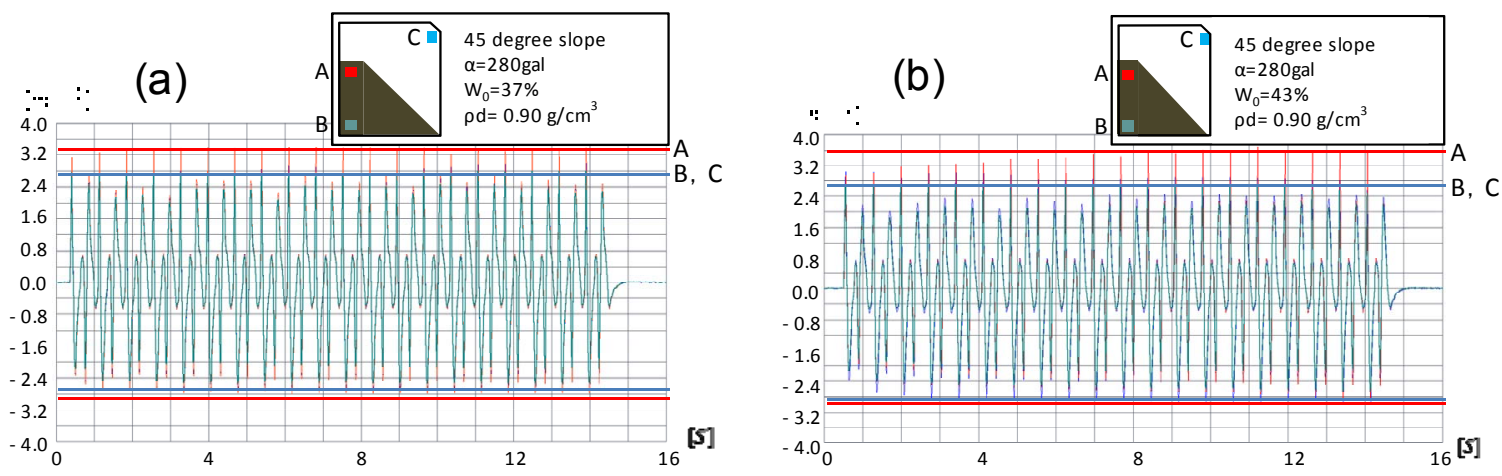

Figure 25. Variation of accelerations at basement, crown of slopes and shaking table: (a) $w_{0}=37 \%$, (b) $w_{0}=43 \%$

Figure 26 (a) and (b) depicts the behavior of pore water pressure normalized by the initial effective overburden pressure $\sigma_{v 0}$ ' under the same conditions. It is obvious that pore water pressure varies regularly with cyclic loadings for $w_{0}=37 \%$. On the other hand, the ratio for $w_{0}=43 \%$ is over $\Delta \mathrm{u} / \sigma_{v 0}{ }^{\prime}=1$, which indicates initial liquefaction. However, slope failure did not occur during cyclic loadings. This implies that a volcanic slope with $w_{0}=43 \%$ appears to have cyclic mobility as has been observed in dense sand. It is interesting that a similar tendency with dense sand is observed for Komaoka volcanic slopes comprised of fine particles.
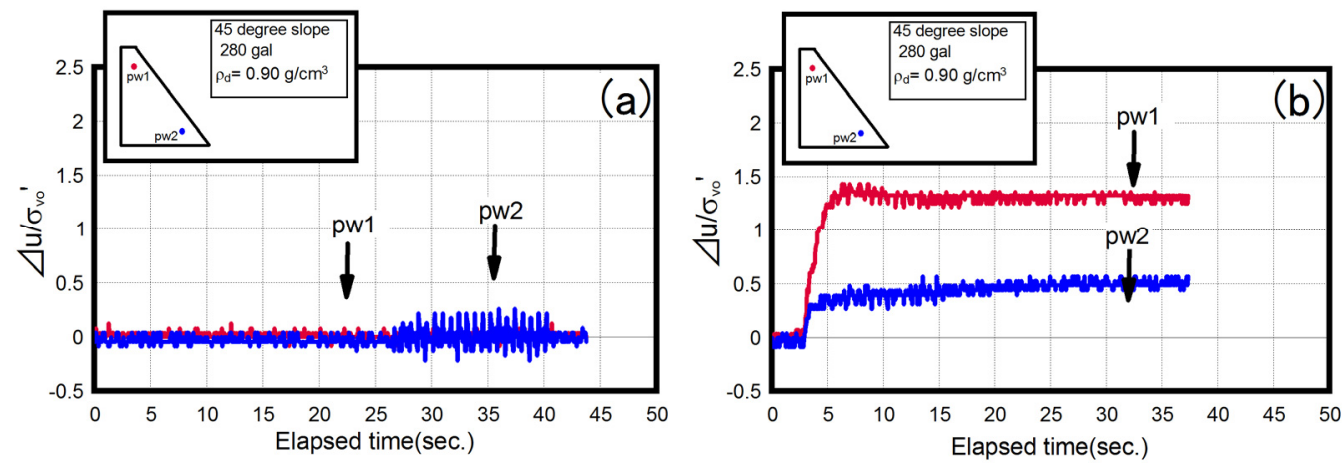

Figure 26. Changes in pore water pressure during shaking table test: (a) $w_{0}=37 \%$, (b) $w_{0}=43 \%$
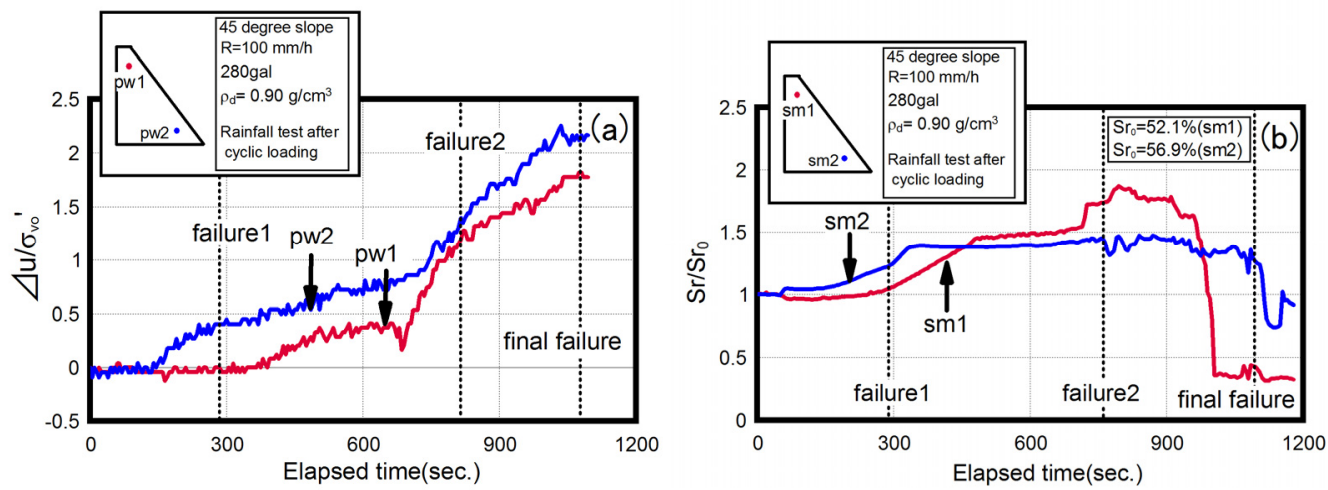

Figure 27. Changes in pore water pressure and saturation degree during rainfall test after cyclic loadings for $w_{0}=37 \%$ : (a) pore water pressure, (b) saturation degree

Finally, rainfall-induced failure of volcanic slopes was investigated for both water contents. As aforementioned, the rainfall model tests were conducted after cyclic loadings. Figure 27 (a) and (b) shows the behavior of pore water pressure normalized by the initial effective overburden pressure, and the changes in degree of saturation, respectively. In the cases of the model tests, a shear strain of $\gamma=2.8 \%$ was generated for the model slope for 
$w_{0}=37 \%$ with a prior cyclic loading of 280 gal. In this case, pore water pressure and the degree of saturation at basement (pw2 and sm2) gradually increase with elapsed time. Owing to these developments of pore water pressure and saturation degree, the first slope failure (failure 1) is induced at the toe of slope, and then the second slope failure (failure 2) is generated by the developments of pore water pressure and saturation degree at the crown (pw1 and sm1). Thereafter, the model test was continued until it reached the same depth as the slip line at $38 \%$ (final failure). Photograph 6 illustrates the schematics of slope shapes during model tests. It is evident that the failure pattern is almost the same as that without cyclic loading (rainfall only, see Photograph 3 (b), Figure 12 (a) and Figure 13 (a)).

Similarly, the data on both pore water pressure and the degree of saturation for $w_{0}=43 \%$ are exhibited in Figure 28 (a) and (b). A shear strain of $\gamma=1.6 \%$ was caused by cyclic loading of 280 gal for the model slope of $w_{0}=43 \%$ in advance. Rainfall-induced failure does not occur for this case although pore water pressure exhibits a high value, as shown in Figure 28 (a). This is due to the increases of both slope density and saturation degree derived by cyclic loadings. Actually, in comparison with the initial state, the degree of compaction $D_{\mathrm{c}}$ increased up to $23 \%$, and the degree of saturation increased to $1 \%$ after cyclic loadings (see Figure 28 (b)). A similar tendency was confirmed for model slopes having $\gamma=1.6 \%-4 \%$ for $w_{0}=43 \%$. In contrast, slope failure occurred for model slopes having less than $\gamma=1.6 \%$.
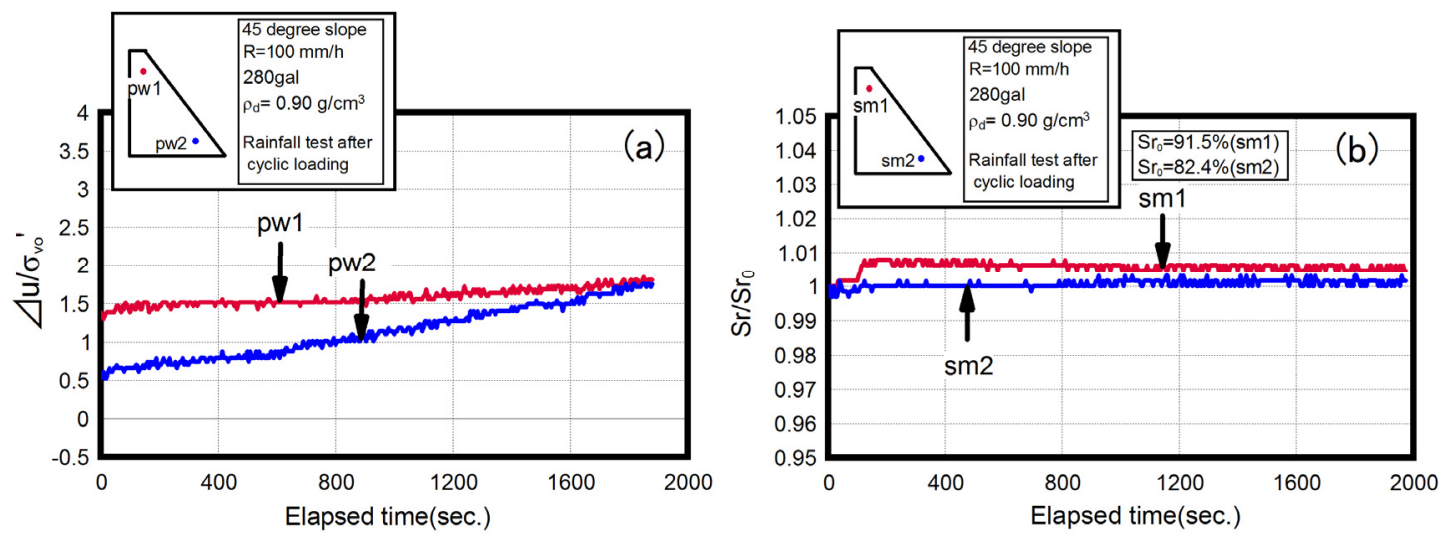

Figure 28. Changes in pore water pressure and saturation degree during rainfall test after cyclic loadings for $w_{0}=43 \%$ : (a) pore water pressure, (b) saturation degree

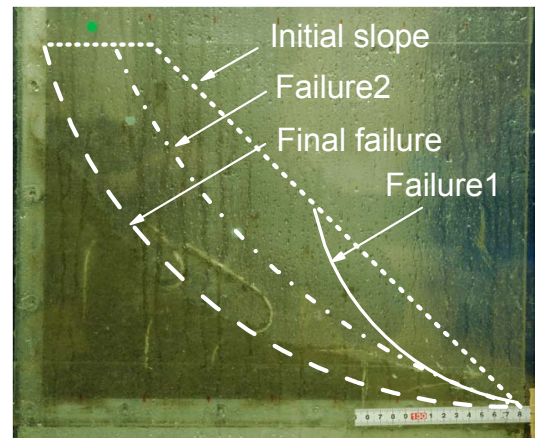

Photograph 6. Schematics of failed slope shape for $w_{0}=37 \%$

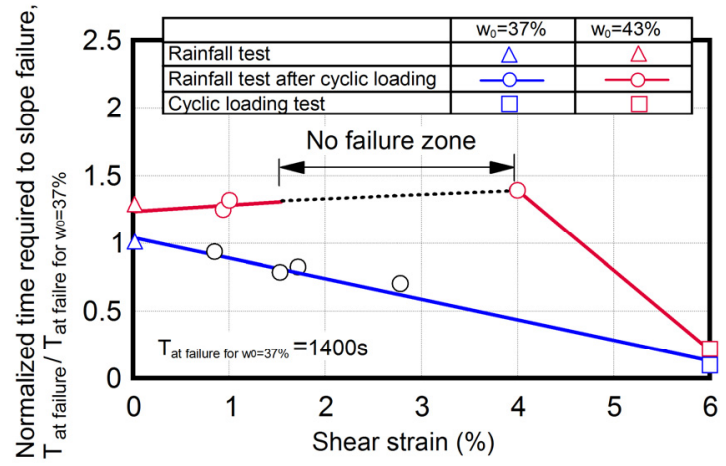

Figure 29. Changes in saturation degree after cyclic loadings for $w_{0}=43 \%$

Figure 29 summarizes the relationship between the elapsed time at final failure for each case normalized by that of rainfall-induced failure of slopes for $w_{0}=37 \%$ and shear strain induced by cyclic loadings. It is apparent that the elapsed time at failure decreases with an increase of shear strain for the case of $w_{0}=37 \%$, and that the time slightly increases until $\gamma=1 \%$ and decreases for more than $\gamma=4 \%$ for the case of $w_{0}=43 \%$. Specifically, there is no failure zone in the range of $1.6 \%$ to $4 \%$ for the case of $w_{0}=43 \%$. Slope failure seems to differ depending on the stress-strain history due to cyclic loadings. 
Figure 15 also shows the relationship between water content at failure and initial water content for all data (including test data of freeze-thaw action cases and cyclic loading tests). It is conspicuous that there are unique relationships between both water contents as well as those without freeze-thaw action although water content at failure decreases for freeze-thaw action. This indicates that void structures of constituent particles are loose structures due to freezing and thawing. In addition, water content at rainfall-induced failure after cyclic loadings seems to be on the line for freeze-thaw action when shear strain is larger for Komaoka volcanic slopes having $w_{0}=37 \%$, and to be on the line of no freeze-thaw action when shear strain is relatively smaller for $w_{0}=43 \%$. A possible reason for this is the changes in fabric structures induced by cyclic loadings, and similarly for those with freeze-thaw action. As a result, it can also be said that slope failure can be predicted if the water retention capacity in a slope is estimated for a volcanic slope subjected to rainfall and cyclic loadings in cold regions, as shown in Equation (1).

Considering the model tests presented above, the failure mechanisms of volcanic slopes in cold regions were clarified and an evaluation method was investigated. However, the above results may change with variations in soil materials and inherent errors such as scale effect. In any case, further investigations in this direction are required.

\section{Conclusions}

On the basis of the limited amount of model testing conducted in this study, the following conclusions were derived.

(1) Surface slope failure changes depending strongly on the initial water content.

(2) The softening of the slope by freeze-thaw action is important for evaluating the stability of volcanic slopes; in particular, its effect is attributed to the reduction of the shearing resistance due to particle breakage, and cannot be ignored for the evaluation of slope stability.

(3) A slope subjected to freezing and thawing deforms perpendicularly and in an upward direction on its surface for freezing, and its direction changes to a gravitational course for thawing. In this case, it has already been in the plastic equilibrium state.

(4) The effect of stress-strain history due to cyclic loadings on the failure mechanisms of volcanic slopes is significant for the evaluation of slope stability.

(5) Rainfall-induced failure can be uniquely assessed by the changes in water content in zones subjected to freezing and thawing, or to shearing deformation due to cyclic loadings.

\section{Acknowledgements}

The authors wish to express their sincere gratitude to Messrs; R. Yamada, Y. Sato, M. Ashihara, K. Okuda, H. Nakano and H. Ino, who conducted a major part of the experiments (Muroran Institute of Technology, Japan), and Dr. S. Yokohama (Hokkaido University, Japan). This study was undertaken with supports of Hokkaido Regional Development Bureau (Sapporo bureau, Sapporo Road Office) and with the financial supports of KAKENHI (Grant-in-Aid for Science Research (A) No. 23241056 and (C) No. 24560597), Japan Society for the Promotion of Science, and River Maintenance Fund (No.25-1151-001), River Foundation, Japan.

\section{References}

Cascini, L., Cuomo, M., Pastor, M., \& Sacco, C. (2013). Modelling the post-failure stage of rainfall-induced landslides of the flow type. Canadian Geotechnical Journal, 50, 924-934. http://dx.doi.org/10.1139/cgj-2012-0375

Fukutsu, K., Kawamura, S., \& Miura, S. (2014). Numerical analysis on slope failure of embankment constructed by volcanic soil. 49th Japan National Conference on Geotechnical Engineering, JGS (in Japanese, in press).

Harries, C., \& Davies, M. C. R. (2000). Gelifluction: Observations from large-scale laboratory simulations. Arctic, Antarctic and Alpine Research, 32(2), 202-207.

Huang, A. B., Lee, J. T., Ho, Y. H., Chiu, Y. H., \& Cheng, S. Y. (2012). Stability monitoring of rainfall-induced deep landslides through pore water profile measurements. Soils and Foundations, 52(4), 737-747. http://dx.doi.org/10.1016/j.sandf.2012.07.013

Ishikawa, T., Miura, S., \& Tokoro, T. (2009). Effect evaluation of freeze-thaw action on hydro-mechanical behavior of unsaturated granular materials. Proceedings of the $17^{\text {th }}$ International Conference on Soil Mechanics and Geotechnical Engineering, ISSMGE, (1), 833-836. 
Ishikawa, T., Miura, S., \& Ito, K. (2010). Influence of freeze-thaw action on mechanical behavior of unsaturated crushable volcanic soil. Proceedings of the $5^{\text {th }}$ International Conference on Unsaturated Soils (pp. 549-554).

Japanese Geotechnical Society [JGS]. (2004). Reconnaissance report of the 2003 Tokachi-oki Earthquake, The Reconnaissance Committee of 2003 Tokachi-oki Earthquake (in Japanese).

Japanese Geotechnical Society [JGS]. (2009). Test method for soil compaction using a rammer (JGS 0711-2009), Standards of Japanese Geotechnical Society, JGS. (in Japanese)

Japanese Geotechnical Society [JGS], Hokkaido Branch. (2010). A guideline on countermeasures on frost-heaving damage of slopes, The Research Committee in Hokkaido Branch, JGS (pp. 1-125) (in Japanese).

Japanese Geotechnical Society [JGS], Hokkaido Branch. (2011). Volcanic soils for engineers - characteristics, design, construction and disasters. The Research Committee in Hokkaido Branch, JGS (pp. 1-130) (in Japanese).

Kaiya, N., Kawamura, S., \& Miura, S. (2013). Field monitoring of volcanic slope in cold region and its evaluation. 48th Japan National Conference on Geotechnical Engineering, JGS (pp. 195-196) (in Japanese).

Kawamura, S., Miura, S., Ishikawa, T., \& Yokohama, S. (2010a). Rainfall-induced failure of unsaturated volcanic slope subjected to freeze-thaw action and its evaluation. Journal of Geotechnical Engineering, JSCE, C-66(3), 577-594 (in Japanese).

Kawamura, S., Miura, S., \& Yokohama, S. (2010b). Mechanical behavior of anisotropic sand ground beneath structures subjected to cyclic loading such as wave loading. Soils and Foundations, 50(5), 645-657.

Kawamura, S., \& Miura, S. (2011). Stability evaluation of slope subjected to rainfall and freeze-thaw actions based on field monitoring. Advances in Civil Engineering (Online Access Journal), 2011, 14 pages. Hindawi Publishing Corporation. http://dx.doi.org/10.1155/2011/867909

Kawamura, S., \& Miura, S. (2013). Rainfall-induced failures of volcanic slopes subjected to freezing and thawing. Soils and Foundations, 53(3), 443-461. http://dx.doi.org/10.1016/j.sandf.2013.04.006

Kawamura, S., \& Miura, S. (2014). Failure of volcanic slopes in cold regions and its prediction, Thematic issue of the Italian workshop on Landslides. Procedia Earth and Planetary Science (in press).

Kazama, M., Kataoka, S., \& Uzuoka, R. (2012). Volcanic mountain area disaster caused by the Iwate-Miyagi Nairiku Earthquake of 2008, Japan. Soils and Foundations, 52(1), 168-184. http://dx.doi.org/10.1016/j.sandf.2012.01.003

Kudo, A. (2013). Damage and restoration for slope failure in Route 230. Tsuchi-to- Kiso, JGS, 61(3), 30-31 (in Japanese).

Miura, S., Yagi, K., \& Kawamura, S. (1996). Static and cyclic shear behavior and particle crushing of volcanic coarse grained soils in Hokkaido. Journal of Geotechnical Engineering, JSCE, III-36(547), 159-170 (in Japanese).

Miura, S., Yagi, K., \& Asonuma, T. (2003). Deformation-strength evaluation of crushable volcanic soils by laboratory and in-situ testing. Soils and Foundations, 43(4), 47-57. http://dx.doi.org/10.3208/sandf.43.4_47

Mori, T., Tobita, Y., \& Okimura, T. (2012). The damage to hillside embankments in Sendai city during the 2011 off the Pacific coast of Tohoku earthquake. Soils and Foundations, 52(5), 910-928. http://dx.doi.org/10.1016/j.sandf.2012.11.011

Nakata, T., \& Miura, S. (2006). Changes in void structures due to particle breakage of volcanic coarse-grained soil, Journal of Geotechnical Engineering, JSCE, C-63(1), 243-236 (in Japanese).

Oka, F., Tsui, P., Kimoto, S., \& Kato, R. (2012). Damage patterns of river embankments due to the 2011 off the Pacific coast of Tohoku earthquake and a numerical modeling of the deformation of river embankments with a clayey subsoil layer. Soils and Foundations, 52(5), 890-909. http://dx.doi.org/10.1016/j.sandf.2012.11.010

Okamura, M., Tamamura, S., \& Yamamoto, R. (2013). Seismic stability of embankments subjected to pre-deformation due to foundation consolidation. Soils and Foundations, 53(1), 11-12. http://dx.doi.org/10.1016/j.sandf.2012.07.015 
Olivares, L., Damiano, E., Greco, R., Zeni, L., Picarelli, L., Minardo, A., \& Bernini, R. (2009). An instrumented flume to investigate the mechanics of rainfall-induced landslides in unsaturated granular soils. Geotechnical Testing Journal, ASTM, 32(2), 108-118.

Orense, R., Farooq, K., \& Towhata, I. (2004). Deformation behavior of sandy slopes during rainwater infiltration. Soils and Foundation, 44(2), 15-30. http://dx.doi.org/10.3208/sandf.44.2_15

Unno, T., Kazama, M., Uzuoka, R., \& Sento, N. (2006). Changes of moisture and suction procedure of volcanic sand induced by shaking disturbance. Soils and Foundations, 46(4), 519-528. http://dx.doi.org/10.3208/sandf.46.519

Uzuoka, R., Sento, N., Kazama, M., \& Unno, T. (2005). Landslides during the earthquakes on May 26 and July 26, 2003 in Miyagi, Japan. Soils and Foundations, 45(4), 149-163.

White, D. G., Take, W. A., \& Bolton, M. D. (2003). Soil deformation measurement using particle image velocimetry (PIV) and photogrammetry. Geotechnique, 53(7), 619-631. http://dx.doi.org/10.1680/geot.2003.53.7.619

Yagi, K., \& Miura, S. (2004). Evaluation of mechanical characteristics for crushable volcanic soil ground. Journal of Geotechnical Engineering, JSCE, III-66(757), 221-234 (in Japanese).

Yamazaki, T., Tomojiri, S., \& Sasaki, T. (2000). Highway Technology. Research Institute, Japan Highway Public Corporation, 16, 75-81 (in Japanese).

\section{Copyrights}

Copyright for this article is retained by the author(s), with first publication rights granted to the journal.

This is an open-access article distributed under the terms and conditions of the Creative Commons Attribution license (http://creativecommons.org/licenses/by/3.0/). 